NASA

Technical Memorandum 102447

AIAA-90-0669
AVSCOM

Technical Memorandum 89-C-014

\title{
Liquid Water Content and Droplet Size Calibration of the NASA Lewis Icing Research Tunnel
}

Robert F. Ide

Propulsion Directorate

U.S. Army Aviation Research and Technology Activity-AVSCOM Lewis Research Center

Cleveland, Ohio

Prepared for the

28th Aerospace Sciences Meeting

sponsored by the American Institute of Aeronautics and Astronautics Reno, Nevada, January 8-11, 1990 


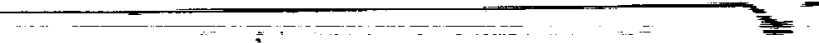

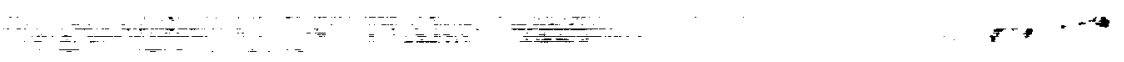




\title{
LIQUID WATER CONTENT AND DROPLET SIZE CALIBRATION
}

\author{
OF THE NASA LEWIS ICING RESEARCH TUNNEL \\ Robert F. Ide \\ Propulsion Directorate \\ U.S. Army Aviation Research and Technology Activity - AVSCOM \\ Lewis Research Center \\ Cleveland, Ohio 44135
}

\begin{abstract}
SUMMARY
The icing research tunnel at the NASA Lewis Research Center underwent a major rehabilitation in 1986-87, necessitating recalibration of the icing cloud. This report describes the methods used in the recalibration, including the procedure used to establish a uniform icing cloud and the use of a standard icing blade technique for measurement of liquid water content. PMS Forward Scattering Spectrometer and Optical Array probes were used for measurement of droplet size. Examples of droplet size distributions are shown for several median volumetric diameters. Finally, the liquid water content/droplet size operating envelopes of the icing tunnel are shown for a range of airspeeds and are compared to the FAA icing certification criteria.
\end{abstract}

\section{INTRODUCTION}

The icing research tunnel at NASA Lewis Research Center in Cleveland, Ohio went through a major rehabilitation in 1986-87. A new drive motor and an automated system for controlling airspeed and icing spray conditions were installed. Eight new spray bars were built to replace the six original bars and new spray nozzles were acquired.

A diagram of the icing research tunnel is shown in figure 1 . The test section is $9 \mathrm{ft}$ wide by $6 \mathrm{ft}$ high by $20 \mathrm{ft}$ long. The tunnel has the capability to run at temperatures from $28^{\circ} \mathrm{F}$ to $-20^{\circ} \mathrm{F}$ at airspeeds from 50 to $300 \mathrm{mph}$.

The changes in the icing tunnel necessitated a recalibration of the spray clouds. The recalibration included flow calibration of the new nozzles; establishment of nozzle locations in the new spray bars to form uniform icing clouds; and measurement of the liquid water content and droplet size distributions of these clouds as a function of air and water pressures applied to the nozzles.

This paper describes the methods used in the recalibration of the icing tunnel and presents the results of this work.

\section{NOZZLE FLOW CALIBRATION}

Figure 2 shows a cross section view of a spray bar with nozzle installed and figure 3 shows a cross section of the nozzle only. Two different nozzles are used in the NASA Icing Research Tunnel. They are referred to as the "standard" and "mod-1" nozzles. Both nozzles are air-assist atomizers, that is, air is used to break up the water stream. In order to establish any water 
flow the water pressure must be higher than the air pressure. Note that the two nozzles differ only in the diameter of the water tube. The smaller diameter water tube of the mod-l nozzles reduces the water flow and droplet size compared to the standard nozzle operating at the same condition.

During rehabilitation of the icing tunnel 150 new standard nozzles and 200 mod-1 nozzles were acquired. A flow test was performed on each nozzle in order to determine the flow coefficient. Water flow coefficient, $C_{f}$, is defined as:

$$
C_{f}=\frac{\dot{W}}{\sqrt{d P}}
$$

where $\dot{W}$ is the water flow rate in gallons/minute and dP is the differential pressure between the water and air supplied to the nozzle in pounds/inch 2 .

Table I shows the conditions at which each nozzle was tested. The first condition was used to test the survivability of the nozzles. It was assumed that if the nozzle could withstand a water pressure of $400 \mathrm{psig}$, then the water tube would not blow out during normal operations.

Figure 4 shows the effect of air pressure and delta pressure on flow coefficient. It can be seen that the flow coefficient does not vary by more than \pm 3 percent except for the 150 psia air pressure at the lowest delta pressure. Flow tests at this condition were repeated three times. The differences shown between tests were traced to calibration errors in the test setup and inaccuracles of the flowmeter at this water pressure and low water flow, illustrating typical problems that can occur during nozzle testing. The data for this flow condition were disregarded.

Since the varlation of flow coefficlent with changes in air pressure and delta pressure were within \pm 3 percent and did not exhibit any strong trends the flow coefficient was assumed to be constant. Nozzles used in the new spray system all have flow coefficients that are within \pm 5 percent of the average flow coefficlent. This variation from nozzle to nozzle was deemed to be acceptable since a liquid water content variation of this amount is acceptable for most icing tests. The average flow coefficient for the standard nozzles is 0.0120 ; the average flow coefficient for the mod-1 nozzles is 0.00406 .

\section{LIQUID WATER CONTENT UNIFORMITY}

The next step was installation of the nozzles in the spray bars and establishment of a uniform icing cloud in the test section.

The uniformity of liquid water content was assessed by accreting ice on 2-in. diameter pipes placed in the tunnel test section. These pipes were placed at nine horizontal positions across the test section. Due to excessive buffeting caused by airflow over the pipes only five pipes could be used at a time, thereby requiring two icing runs to document the uniformity across the whole test section. The center pipe was used during both runs. 
Figure 5 shows a picture of the pipes in the test section. Figure 6 shows a cutaway of the typical ice shape accreted on the pipes. The proper ice shape must conform to the shape of the pipes and is controlled by adjusting liquid water content, droplet size and the duration of the spray.

The girth of the iced pipes was measured at two-inch vertical increments, resulting in 310 measurements for each spray. All measurements were then converted to relative liquid water content normalized to the measurement at the center of the tunnel using the equation:

$$
\frac{\operatorname{LWC}(x, y)}{\operatorname{LWC} C_{C}}=\frac{C(x, y)-C_{p i p e}}{C_{C}-C_{p i p e}}
$$

where $c(x, y)$ is the circumference of the iced pipe at each location, $c_{c}$ is the iced circumference at the center location, and $C_{p i p e}$ is the uniced circumference of the pipe. This data was input to a contour plotting package.

The nozzles were initially placed in a uniform hexagonal array. Since 77 nozzles were used in the original IRT nozzle array, the same number of nozzles were used in this configuration. It was assumed that, since the nozzles had closely matched flow coefficients, this pattern would evenly distribute the water throughout the test section. However it was found that this nozzle pattern resulted in a very nonuniform cloud.

Nozzles were moved and added to fill low liquid water content regions of the cloud but it was found that there did not appear to be a direct spacial relationship between nozzle placement in the spray bars and the resulting liquid water content in the test section. This behavior of the cloud was presumed to be caused by nonuniform airflow over the spraybars and through the tunnel contraction.

In order to determine where the spray from different nozzle locations ended up when it reached the test section, a series of runs were made using two widely spaced spray bars at a time. The peak ice thicknesses on the vertical pipes was then recorded. The test was repeated using vertical lines of nozzles at ten different horizontal locations and accreting ice on horizontal bars.

Figure 7 shows the results of these tests. The numbers on each end of the wavy horizontal lines correspond to the spray bars and the numbers on each end of the vertical lines correspond to the vertical lines of nozzles. It can be seen that the spray is generally pushed away from the center of the walls, floor and ceiling. This behavior causes concentration of the icing cloud in some areas while creating relative voids in other areas.

The information gained from the single spray bar tests made the movement and addition of nozzles to the spray system more systematic. However the process of establishing a uniform cloud still involved considerable trial and error and was very time consuming. The final standard nozzle configuration contained 94 nozzles and the final mod-1 nozzle configuration contained 95 nozzles.

Figure 8 shows the cloud uniformity contour plots for the standard and mod-l nozzles at an airspeed of $145 \mathrm{mph}$. For the standard nozzles the uniform 
liquid water content area is approximately 3 by $4 \mathrm{ft}$. (The uniform area is defined as the area where the liquid water content is within 20 percent of the center value.) The uniform liquid water content area for the mod-1 nozzles is 2 by $3 \mathrm{ft}$.

Figure 9 shows the cloud uniformity contour plots for the standard nozzles at airspeeds of 70 and $220 \mathrm{mph}$. The cloud is uniform over a large area of the test section at $70 \mathrm{mph}$ except for a large low LWC area at the top and a high-LWC area near the bottom. At $220 \mathrm{mph}$ the uniform area is only 1.5 by $2.5 \mathrm{ft}$. This shrinking of the uniform liquid water content area affects the liquid water content calibration as will be discussed in the following section.

\section{LIQUID WATER CONTENT CALIBRATION}

A standard icing blade (ref. 1) was used to measure the liquid water content in the center of the test section. The blade was made of aluminum and was $6 \mathrm{in}$. long, three-fourths of an inch deep and one-eighth of an inch thick. The blade was placed inside the tunnel behind a shield. The tunnel was chilled to $0 \circ \mathrm{F}$ for most tests. The spray conditions were set and allowed to stabilize before the blade was lowered into the cloud at the center of the test section. The exposure time was adjusted to allow between one and three sixteenths of an inch of ice to form on the one-eighth in. leading edge of the blade. The correct exposure time and air temperature resulted in the ice accreting as shown in figure 10.

The thickness of ice on the blade was measured using a chilled micrometer. The ice thickness and the exposure time were used in equation ( 3 ) to calculate liquid water content.

$$
L W C=\frac{C \times \rho_{i c e} \times \Delta S}{E_{b} \times V \times t}=\frac{5.00 \times 10^{4} \times \Delta S}{E_{b} \times V \times t}
$$

where $C$ is a unit conversion constant, pice is the ice density which is assumed to be constant ( $i . e ., \rho j c e=0.88), \Delta S$ is in inches, $E_{b}$ is the blade collection efficiency, $V$ is the freestream velocity in mph and $t$ is the blade exposure time in seconds.

The collection efficiency, $E_{b}$, of the blade was calculated using the FWG two-dimensional trajectory code (ref. 2). This code uses a Hess-Smith panel code for flowfield prediction and a C.W. Gear stiff equation scheme to integrate particle trajectorles.

The icing blade was used to measure the liquid water content over a range of airspeeds, water flow rates and water droplet sizes. Water flow rate and droplet size were controlled by changing the air pressure and water pressure supplied to the nozzles.

The liquid water content calibration of the icing tunnel prior to the 1986 rehabilitation was of the form:

$$
L W C=K \frac{\sqrt{d P}}{V}
$$


where $K$ was a constant for each set of nozzles. For the standard nozzles, $K=40.6$; for the mod-1 nozzles, $K=12.9$.

During the blade measurements and subsequent data analysis it became apparent that "K" was not constant. That is, the liquid water content was not a function of only the delta pressure applid to the nozzles and the tunnel airspeed as in equation (4). Figure 11 shows a plot of "K" for airspeeds from 50 to $250 \mathrm{mph}$. As noted on this figure all other spray parameters were held constant, i.e., tunnel air temperature, nozzle air pressure and delta pressure and droplet size. It can be seen that " $K$ " is a function of the airspeed to the 0.38 power.

It was found that " $K$ " was also a function of nozzle air pressure as shown in figure 12. For this test the airspeed was held constant at $150 \mathrm{mph}$ and the droplet size was held at $20 \mu \mathrm{m}$. The test was initially run with the tunnel air temperature at $0{ }^{\circ} \mathrm{F}$ and the nozzle air temperature set at $175^{\circ} \mathrm{F}$. The test was then repeated at tunnel air temperatures of 10 and -15 of with the nozzle air temperature at 175 of and repeated again at a tunnel air temperature of $0{ }^{\circ} \mathrm{F}$ with nozzle air temperatures of $165^{\circ}$ and $185^{\circ} \mathrm{F}$. It was found that changes in the tunnel air temperature and nozzle air temperature within these ranges caused no systematic changes in the data.

It can be seen from figure 12 that the liquid water content is a function of the nozzle air pressure to the -0.236 power. The most probable reason for this decrease in liquid water content with an increase in nozzle air pressure is that some of the water droplets are freezing out. This freeze-out is due to the temperature decrease of the compressed air as it undergoes an isentropic expansion while exiting the nozzle (refs. 3 and 4 ).

The effect of droplet size on "K" was also investigated. For the standard nozzles, droplet size effects were small as shown in figure 13 . Since the air pressure could not be held constant while the droplet size was varled over the complete range, the " $K$ " values for each data point were adjusted to compensate for the air pressure effects shown in figure 12 . The data are uncorrelated and have a scatter of approximately \pm 6 percent. For the mod-1 nozzles there appears to be a very strong effect of droplet size below $14 \mu \mathrm{m}$ as can be seen in figure 13. There is also considerable data scatter in this region. The reasons for this behavior are not known and need further investigation. Therefore, until the data scatter can be reduced or defined droplet sizes less than $14 \mu \mathrm{m}$ cannot be used for icing tests.

Combining the alrspeed and nozzle air pressure effects on "K" resulted in equation ( 5 ).

$$
\begin{array}{ll}
\begin{array}{l}
\text { Standard } \\
\text { Nozzles }
\end{array} & K=42.0\left(\frac{V}{150}\right)^{0.38}\left(\frac{P_{\text {air }}}{40}\right)^{-0.236} \\
\begin{array}{l}
\text { Mod-1 } \\
\text { Nozzles }
\end{array} & K=12.0\left(\frac{V}{150}\right)^{0.38}\left(\frac{P_{\text {air }}}{60}\right)^{-0.236}
\end{array}
$$


To examine how well these equations fit the measured icing blade data, the "measured K" was calculated from the blade data using the equation:

$$
K=\frac{5.00 \times 10^{4} \times \Delta S}{E_{b} \times t \times \sqrt{d p}}
$$

The " $K$ " calculated from equation (5) was then plotted against the " $K$ " values calculated directly from the blade measurements (equation $(6)$ ) as shown in figure 14. The mod-1 nozzle data for droplet sizes less than $14 \mu \mathrm{m}$ was excluded. It can be seen that almost all of the data lies within a \pm 10 percent band about the line of perfect agreement for both sets of nozzles.

\section{DROPLET SIZE CALIBRATION}

Two droplet sizing instruments were used in the droplet size calibration of the icing research tunnel. These were the Forward Scattering spectrometer Probe (FSSP) and the Optical Array Probe (OAP), both manufactured by Particle Measuring Systems, Incorporated, of Boulder, Colorado. Both of these instruments are aircraft type instruments which could be inserted in the icing tunnel.

The FSSP (refs. 5 and 6) was used to measure droplets with diameters of 2 to $47 \mu \mathrm{m}$. In this instrument a laser beam is used to illuminate single particles as they traverse the sample volume. The forward scattered light is focused onto a photodiode which measures the intensity. The greater the intensity, the larger the particle size. The instrument counts each particle and places the count into one of fifteen size bins. The nominal bin width for this instrument is $3 \mu \mathrm{m}$. In this way, over time, a number versus particle size histogram is obtained. A data analysis program is used to convert the number histogram into a volume histogram and calculate other characteristics of the droplet distribution such as the median volumetric diameter.

The OAP (refs. 5 and 7) was used to measure droplets with diameters of 15 to $310 \mu \mathrm{m}$. In this instrument a collimated laser beam is used to illuminate particles. As a particle passes through the beam its shadow is projected onto a linear photodiode array. The number of diodes shadowed determines into which particle size bin the particle will be placed. The size definition of each size bin is determined by the diode spacing and system magnification. The nominal bin width for this instrument is $20 \mu \mathrm{m}$.

The two instruments were mounted in the tunnel on a traversing mechanism as shown in figure 15. A spray condition (i.e., air pressure and delta pressure) was selected and allowed to stabilize. A $10 \mathrm{sec}$ measurement of the spray was made with the FSSP in the center of the tunnel. The instruments were then traversed until the OAP was positioned in the center of the tunnel. A 40 sec measurement was then made with the OAP. The OAP measurement was longer than the FSSP measurement time in an attempt to acquire adequate statistical data for the lower number density, larger droplets measured by the OAP. Figure 16 shows an example of the FSSP and OAP percent number and percent volume histograms for one spray. 
The data from the FSSP and OAP were then combined into a single droplet distribution. This was done by taking into account the sample area, measurement time and bin widths of each instrument. Due to the fact that the ranges of the two instruments overlap and that the first two bins of the OAP characteristically undercount, the first two bins of the OAP data were disgarded. Figures 17 to 19 show examples of the combined distributions from the two instruments.

Figure 17 shows an example of the combined droplet distribution for an average-sized median volumetric diameter. Median volumetric diameter (MVD) is defined as the diameter where half of the volume of water is contained in droplets with diameters smaller (or larger) than this diameter. Figure 17(a) shows the droplet number distribution which is normalized by the sample volume, in cubic centimeters, and the bin width, in microns, of each instrument. Figure $17(b)$ shows the 1 iquid water content distribution for the same spray, normalized by the instrument bin widths. The shape of the distributions presented in this manner would result from measurement with an instrument that had constant bin widths and sample volumes for all bins. It can be seen that, in the number distribution, the FSSP and OAP data combine quite smoothly with only a small offset. This offset is magnirled in the LWC distribution but has little effect on the calculated MVD. In this case the MVD from the FSSP only was $22.3 \mu \mathrm{m}$ and the MVD from the combined distribution is $22.8 \mu \mathrm{m}$, an increase of only $0.5 \mu \mathrm{m}$.

Figure 18 shows the number and LWC distributions for a small MVD spray. Note that no OAP data appears on this plot. Counts in the OAP were recorded but they are off-scale on these plots. The OAP data has no significance in small MVD sprays.

Figure 19 shows the number and LWC distributions for a large MVD. The number distribution is very smooth but the LWC distribution contains a small secondary peak within the OAP portion. It is not known at this time whether this is caused by an instrument inaccuracy or if the spray is actually starting to become bimodal. Also note that the distribution continues out to $300 \mu \mathrm{m}$, the upper limit of the OAP range. Since the range of the instruments used is exceeded by the width of the droplet size distribution, larger MVD's cannot be measured. This established the upper limit of the droplet size calibration as $40 \mu \mathrm{m}$.

Measurements were made over a wide range of air pressure and delta pressure conditions using the standard and mod-l nozzles. For the standard nozzles, measurements could not be made with the FSSP for delta pressures greater than 100 psid due to the high liquid water content which caused rapid icing of the instrument. Figure 20 shows the results of the droplet size calibration. Droplet size (MVD) is plotted as a function of delta pressure and alr pressure. It can be seen that the MVD increases with increasing delta pressure and increases with decreasing air pressure.

\section{CLOUD ENVELOPES}

The results of the liquid water content and droplet size calibrations were combined to establish the operating envelopes of the spray system. Since liquid water content is a function of the airspeed in the tunnel, these operating envelopes are also a function of airspeed. 
Figure 21 shows the operating envelopes for the icing tunnel at airspeeds of 100,150 and $250 \mathrm{mph}$ for the standard and mod-l nozzles. The mod-l nozzles, which were not included in previous callibrations, significantly increase the range of icing conditions that can be duplicated in the tunnel. These nozzles allow operation of the tunnel at the low liquid water contents which are most frequently requested. However due to the uncertainty of the droplet size effect on the liquid water content calibration which was shown in figure 13 , the mod-l nozzles cannot be used at droplet sizes below $14 \mu \mathrm{m}$.

The other major limiting factors for the boundaries of the standard and mod-1 envelopes is shown on figure 21(a). The apparent freeze-out of droplets as nozzle air pressure is increased results in a 38 percent reduction in the liquid water content of the $80 \mathrm{psig}$ air pressure boundary. This large amount of freeze-out can also have an effect on certain types of icing tests since this amount of water is still contained in the cloud in the form of ice crystals.

As can be seen from figure 21 , at $100 \mathrm{mph}$ a large range of icing conditions can be duplicated. As the tunnel airspeed is increased the range of icing conditions that can be run decreases.

In order to determine how well the icing spray capabilities of the NASA icing research tunnel meet the needs of the icing community the IRT operating envelopes were compared to the Federal Aviation Admistration (FAA) aircraft icing certification standards contained in FAR-25 and FAR-29. The FAR icing envelopes are shown in figure 22.

Figure 23(a) shows the operating envelope of the IRT at $100 \mathrm{mph}$ superimposed on the FAA icing criteria. The IRT can duplicate only the central portion of the FAA criteria. Figure 23(b) shows the operating envelope of the IRT at $250 \mathrm{mph}$ superimposed on the FAA icing criteria. Although the IRT liquid water content range is lower at this speed, it still cannot produce the low liquld water content portion of the FAA criteria. In addition the IRT cannot produce the peak liquid water content levels required by either FAA criteria at the correct droplet size.

The number of nozzles in the icing tunnel could be adjusted to expand the amount of overlap between the tunnel capabilities and the FAA criteria. Any changes in the nozzle array would require recalibration of the liquid water content for each nozzle configuration. Substantial changes in the number of nozzles could have a detrimental effect on the cloud uniformity. The number of different nozzle arrays must also be balanced against the impact on the productivity of the tunnel.

Another possible method of enlarging the icing tunnel envelopes is to use a different spray nozzle. Several surveys of existing spray nozzles have been performed (refs. 8 and 9). A nozzle that is clearly superior to the NASA nozzles has not been found. An investigation of existing spray nozzles and modifications to these nozzles is continuing. 


\section{CONCLUSIONS}

The first complete recalibration of the icing sprays in the NASA Lewis icing research tunnel was accomplished. Extensive measurements were made of the liquid water content and droplet sizes over a wide range of spray conditions.

The airspeed in the icing tunnel was shown to have a significant effect on the liquid water content uniformity within the test section as well as effecting the liquid water content calibration. The air pressure supplied to the spray nozzles was shown to have a significant effect on the measured liquid water content, particularly at high air pressures where droplet freezeout becomes significant.

The droplet size calibration of the icing tunnel encompassed a range of median volumetric diameters from 10 to $40 \mu \mathrm{m}$. This represents a 50 percent increase in the maximum calibrated droplet size, which was formally $20 \mu \mathrm{m}$.

In spite of the expansion in icing tunnel capabilities, the tunnel still cannot duplicate the icing criteria set forth in FAR-25 and FAR-29, particularly the low liquid water content large droplet size and high liquid water content small droplet size regions of these envelopes. Although the tunnel capabilities could be expanded by changing the number of nozzles in the spray system, these changes would require addition calibrations and would impact the productivity of the facility.

\section{RECOMMENDATIONS}

(1) The aerodynamics of the icing tunnel should be measured upstream and downstream of the spray bars in order to determine the influence on the icing cloud uniformity in the test section.

(2) The cause of the large scatter in the liquid water content calibration coefficlent for MVDs smaller than $14 \mu \mathrm{m}$ should be further investigated.

(3) The investigation of other types of spray nozzles should be continued to determine if nozzles are available which would increase the operating range of the spray system without requiring high alr pressures, thereby reducing droplet freezeout.

\section{ACKNOWLEDGEMENTS}

William 01 sen (deceased) performed the cloud uniformity work contained in this report. I wish to thank Annette Sobota for her assistance in the cloud uniformity and icing blade tests. I also thank the icing tunnel personnel for all their assistance. 


\section{REFERENCES}

1. Stallabrass, J.R., "An Appraisal of the Single Rotating Cylinder Method of Liquid Water Content Measurement, "Canadian National Research Council

Report LTR-LT-92, Nov., 1978.

2. Frost, W., "Two-Dimensional Particle Trajectory Computer Program," Interim Report for Contract NAS3-22448, Mar., 1982.

3. Marek, C.J. and Bartlett, C.S., "Stability Relationship for Water Droplet Crystallization With the NASA Lewis Icing Spray," NASA TM-100220, 1988, also AIAA Paper 88-0289.

4. Lazelle, B.D., "Conditions to Prevent Freeze-Out Ouring Atomization of Water Sprays for Icing Cloud Simulation," D. Napier and Son Limited, Bedfordshire, England, 1958.

5. Hovenac, E.A., "Droplet Sizing Instrumentation Used for Icing Research: Operation, Calibration, and Accuracy," NASA CR-182293, Aug. 1989.

6. Dye, J.E. and Baumgardner, D., "Evaluation of the Forward Scattering Spectrometer Probe 1: Electronic and Optical Studies, "Journal of Atmospheric and Oceanic Technology, Vol. I, Dec. 1984, pp. 329-344.

7. Hovenac, E.A., Hirleman, E.D. and Ide, R.F., "Calibration and Sample Volume Characterization of PMS Optical Array Probes, "Presented at the International Conference on Liquid Atomization and Spray Systems, the Third (ICLASS 85), London, England, July, 1985.

8. Peterson, A., and 01denburg, J., "Spray Nozzle Investigation for the Improved Helicopter Icing Spray System (IHISS)," AIAA-90-0666, Jan. 1990, to be published.

9. Hunt, J.D., "Spray Nozzle Calibrations," AEDC-TR-85-65, Jan. 1986.

TABLE I. - TEST CONDITIONS FOR HATER FLOW CALIBRATION

\begin{tabular}{|c|c|c|c|c|}
\hline \multicolumn{4}{|c|}{ OF NASA NOZZLES } \\
$\begin{array}{c}\text { Water } \\
\text { pressure, } \\
\text { psia }\end{array}$ & $\begin{array}{c}\text { Air } \\
\text { pressure, } \\
\text { psia }\end{array}$ & $\begin{array}{c}\text { Delta } \\
\text { pressure, } \\
\text { psid }\end{array}$ & \multicolumn{2}{|c|}{$\begin{array}{c}\text { Average } \\
\text { flow, } \\
\text { gal/min }\end{array}$} \\
\cline { 3 - 5 } & & \multicolumn{2}{|c|}{$\begin{array}{c}\text { Standard } \\
\text { Mod-1 }\end{array}$} \\
\hline 400 & amb & 385 & 0.235 & 0.0797 \\
350 & 150 & 200 & .170 & .0574 \\
230 & 150 & 80 & .107 & .0363 \\
160 & 150 & 10 & .038 & .0128 \\
225 & 25 & 200 & .170 & .0574 \\
105 & 25 & 80 & .107 & .0363 \\
35 & 25 & 10 & .038 & .0128 \\
\hline
\end{tabular}




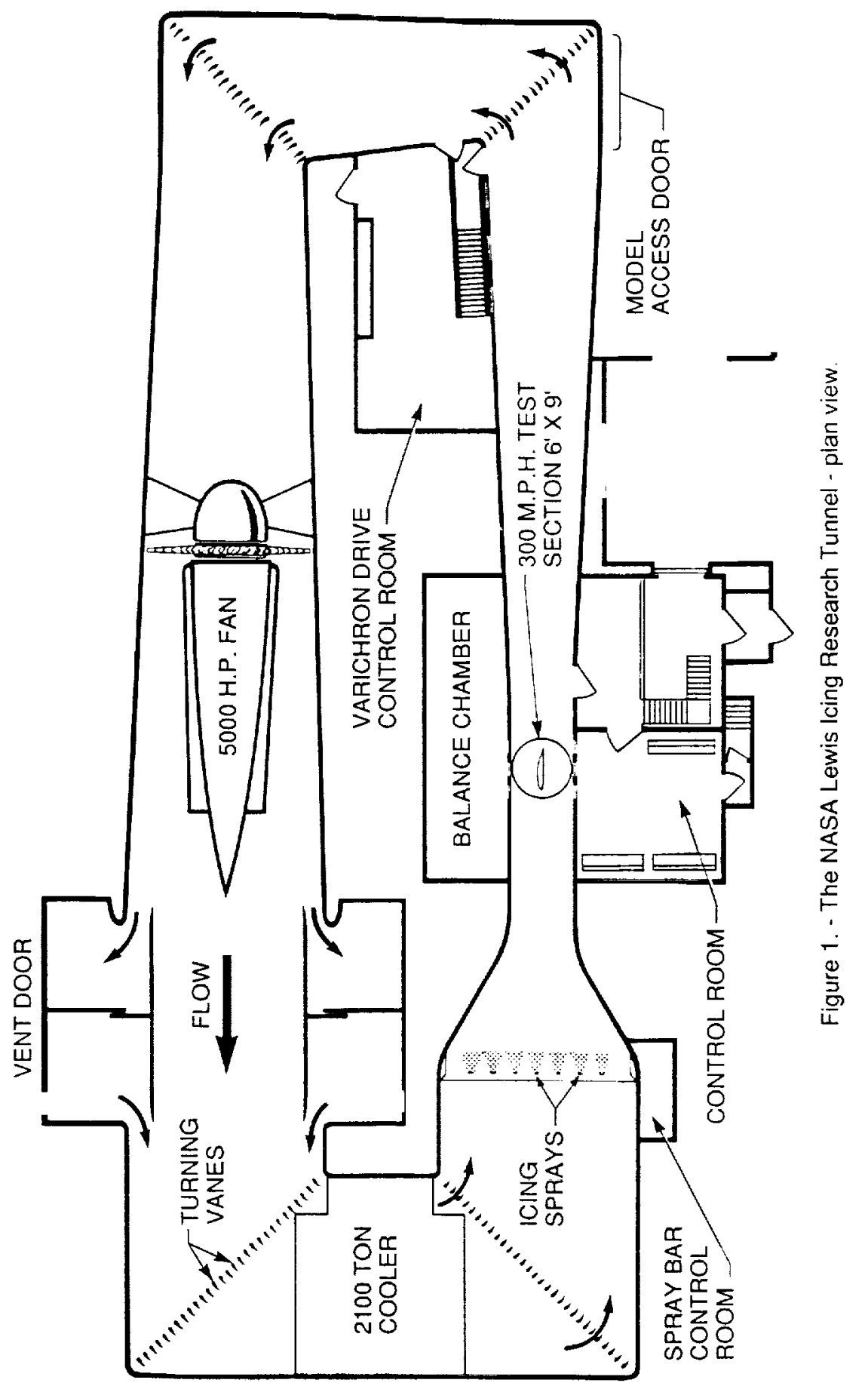




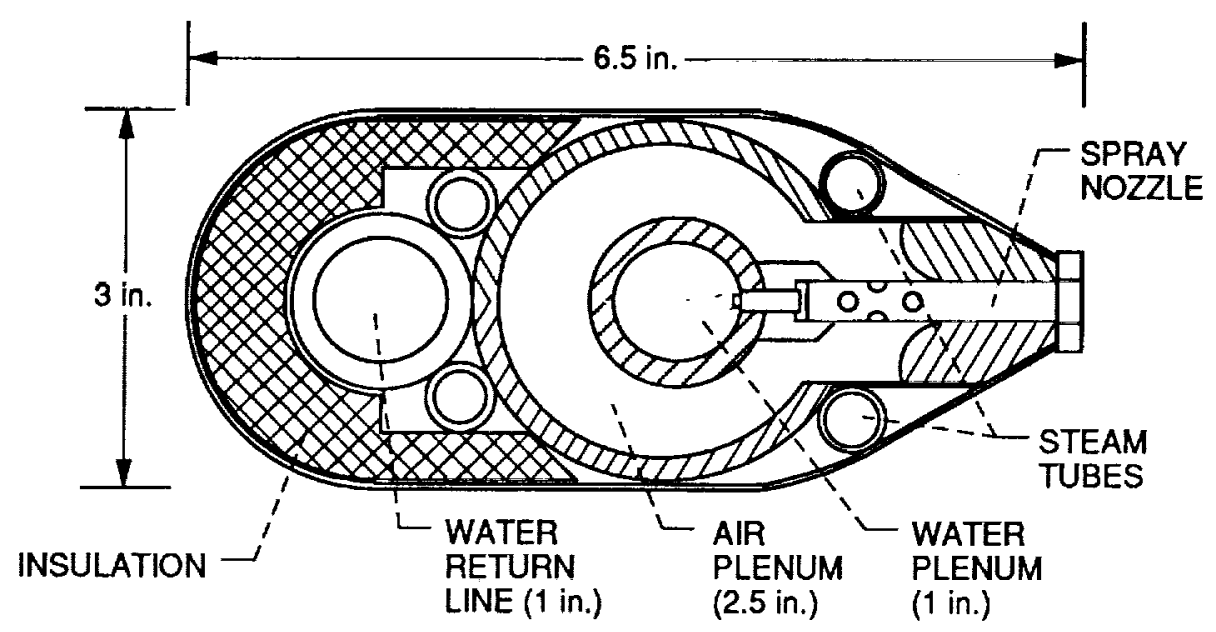

Figure 2. - Cross section view of icing tunnel spray bar.

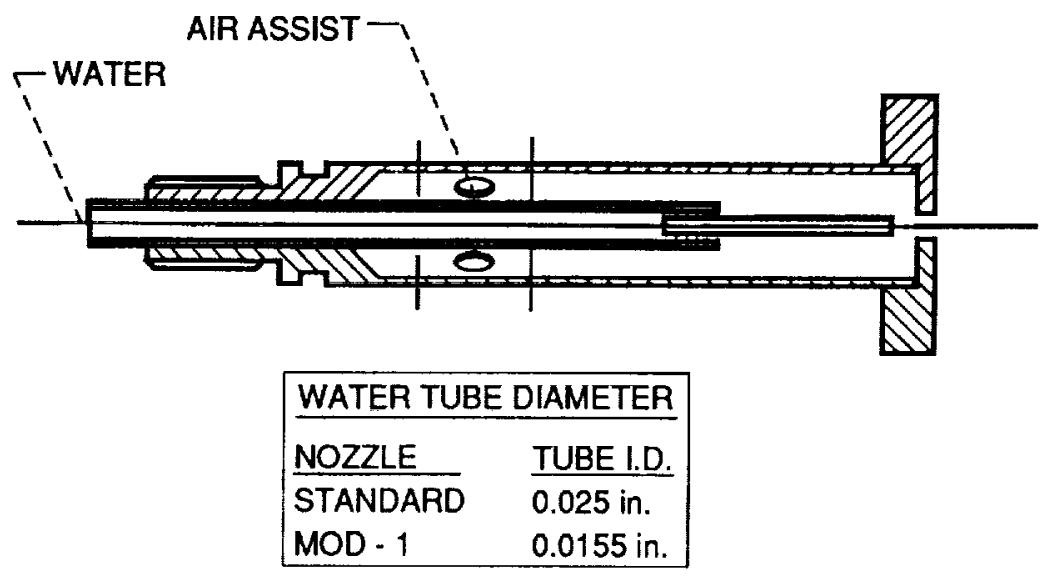

Figure 3. - Icing tunnel spray nozzle. 


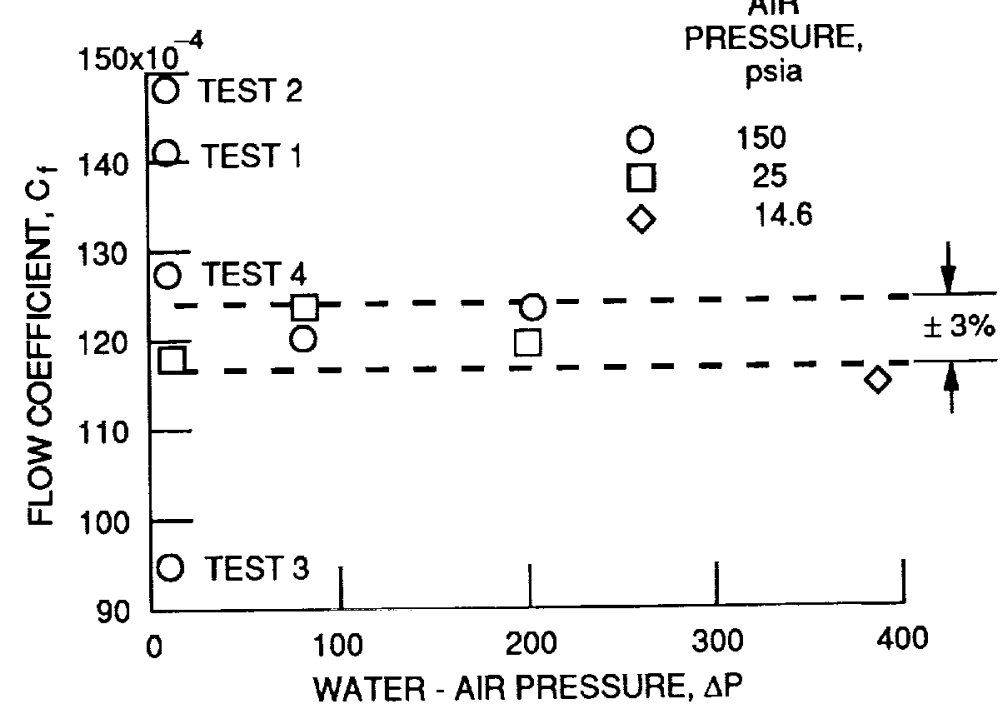

Figure 4. - Effect of air and water pressure on water flow coefficient of IRT spray nozzles.

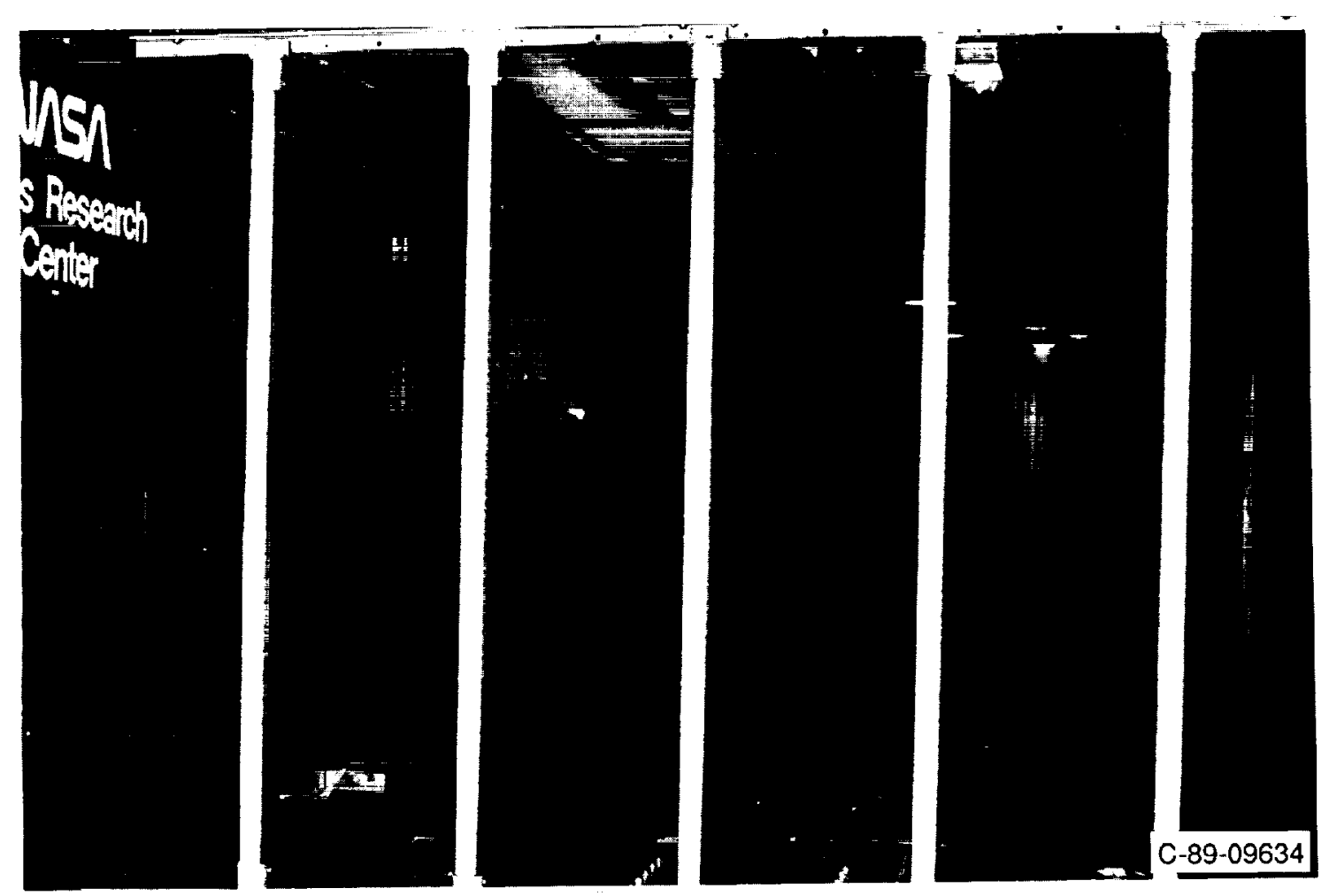

Figure 5. - 2-inch diameter pipes installed in IRT test section. 


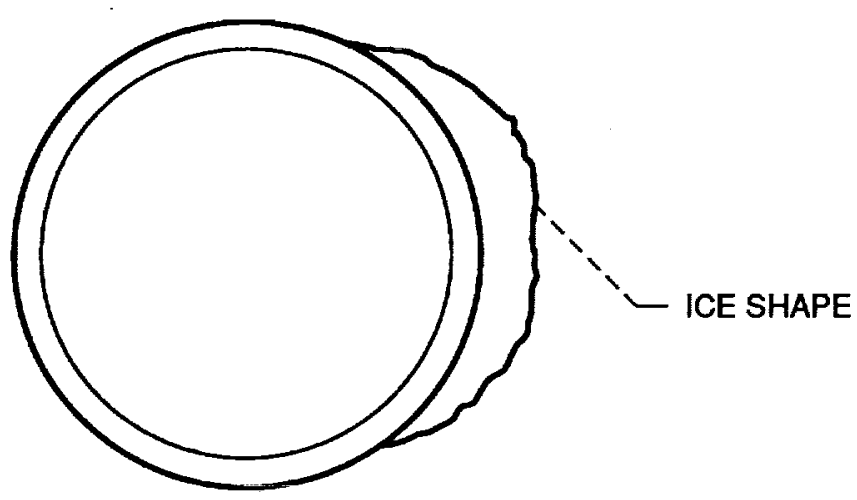

Figure 6. - Typical ice shape on 2 in. cylindrical pipe.

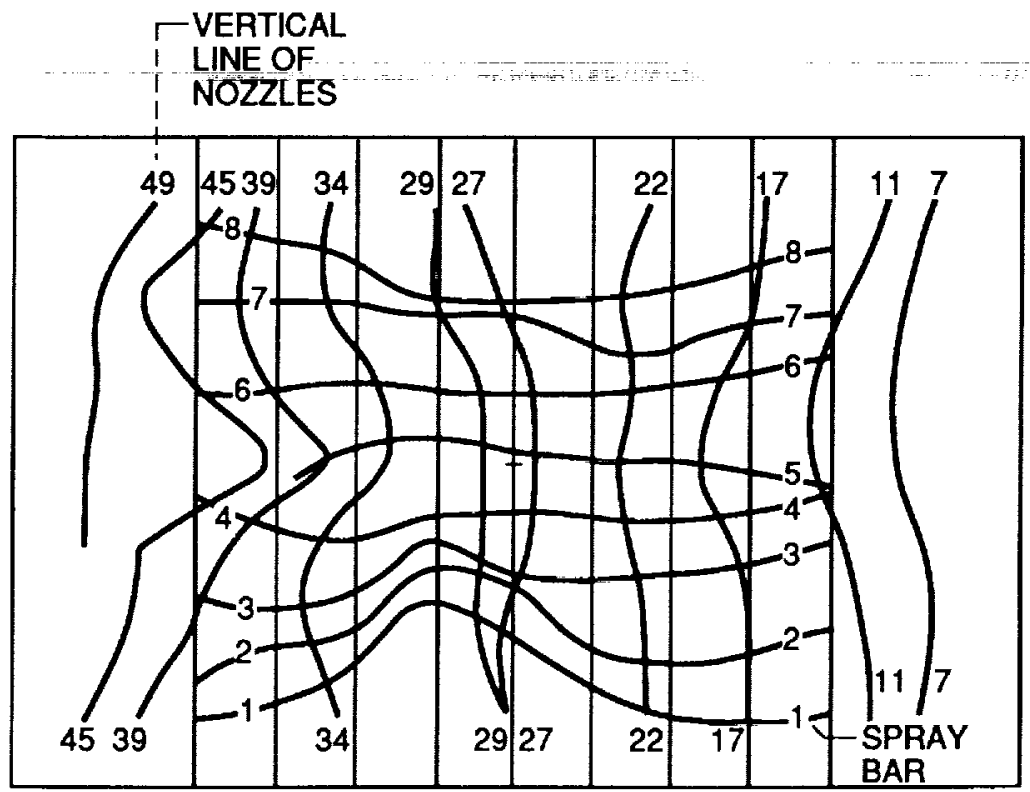

Figure 7. - Map of peak LWC from each spray bar and vertical line of nozzles. 


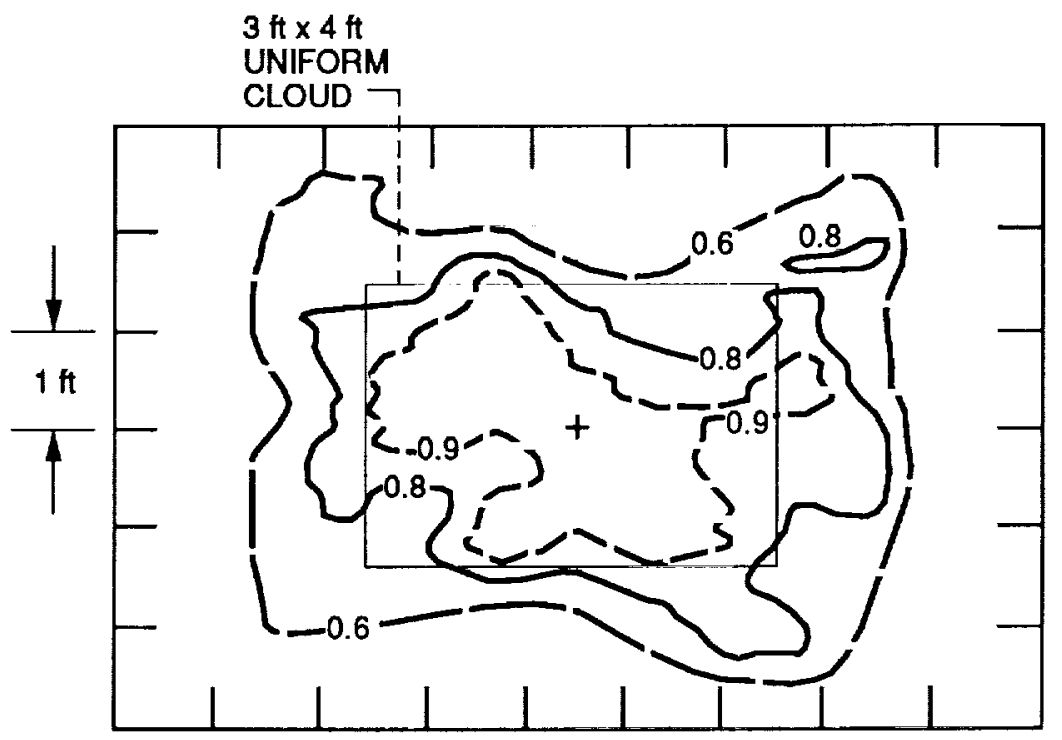

(a) Standard nozzles.

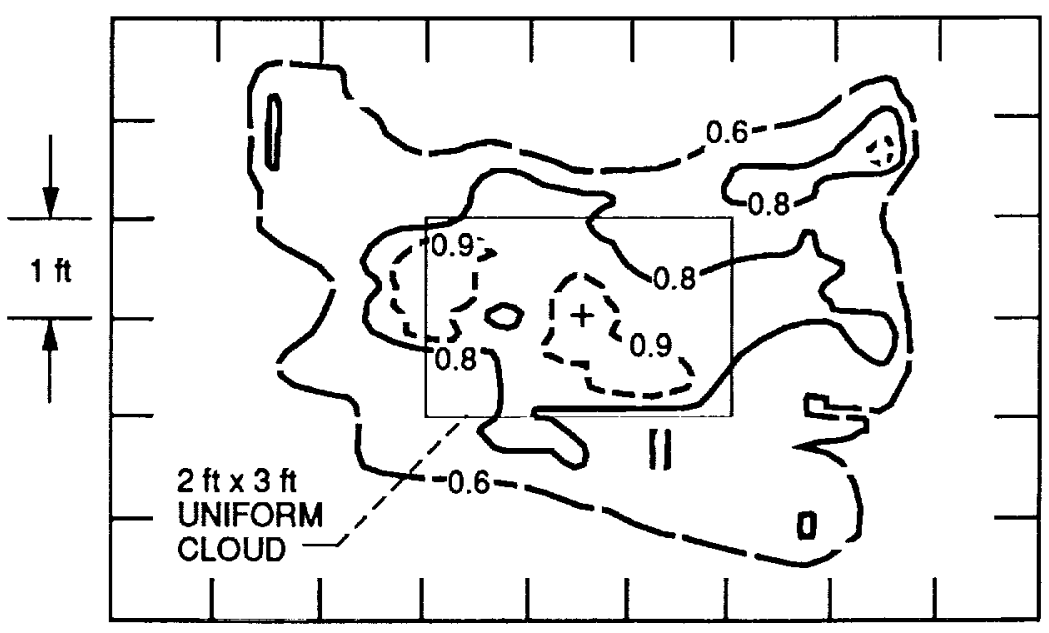

(b) Mod-1 nozzles.

Figure 8. - Liquid water content contour plots for an airspeed of $145 \mathrm{mph}$. 


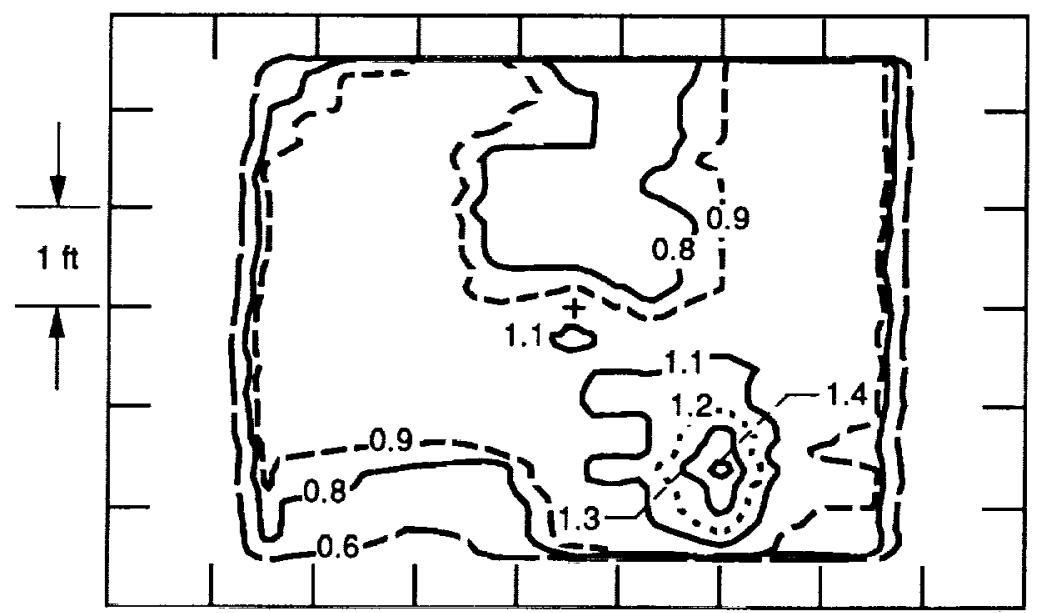

(a) Airspeed = $70 \mathrm{mph}$.

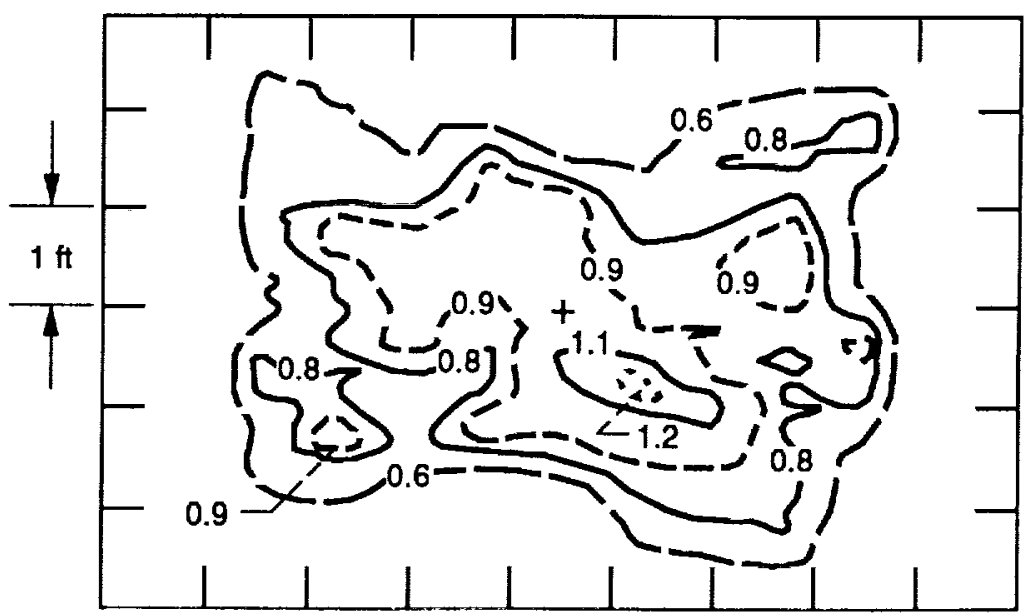

(b) Airspeed $=220 \mathrm{mph}$.

Figure 9. - Liquid water content contour plots for the standard nozzles. 


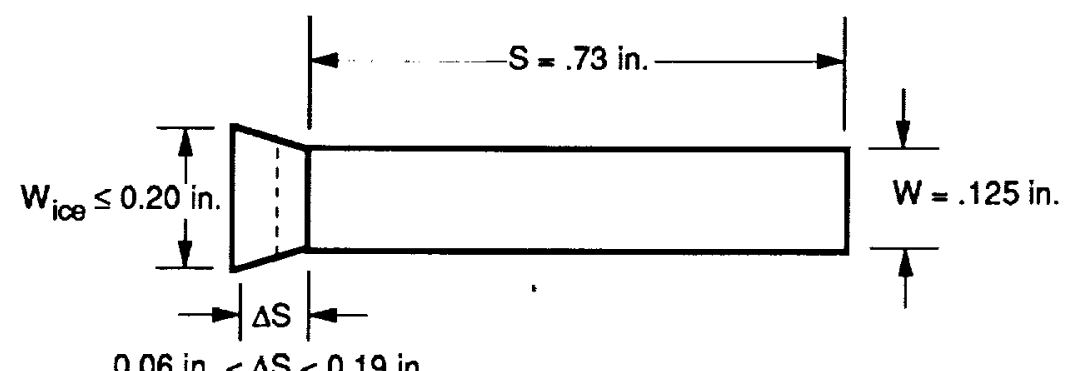

0.06 in. $<\Delta S<0.19$ in.

Figure 10. - Standard lcing blade used to measure liquid water content. Also shown are limits of ice thickness $(\Delta S)$ and ice width $\left(W_{\text {ice }}\right)$ for proper measurement.

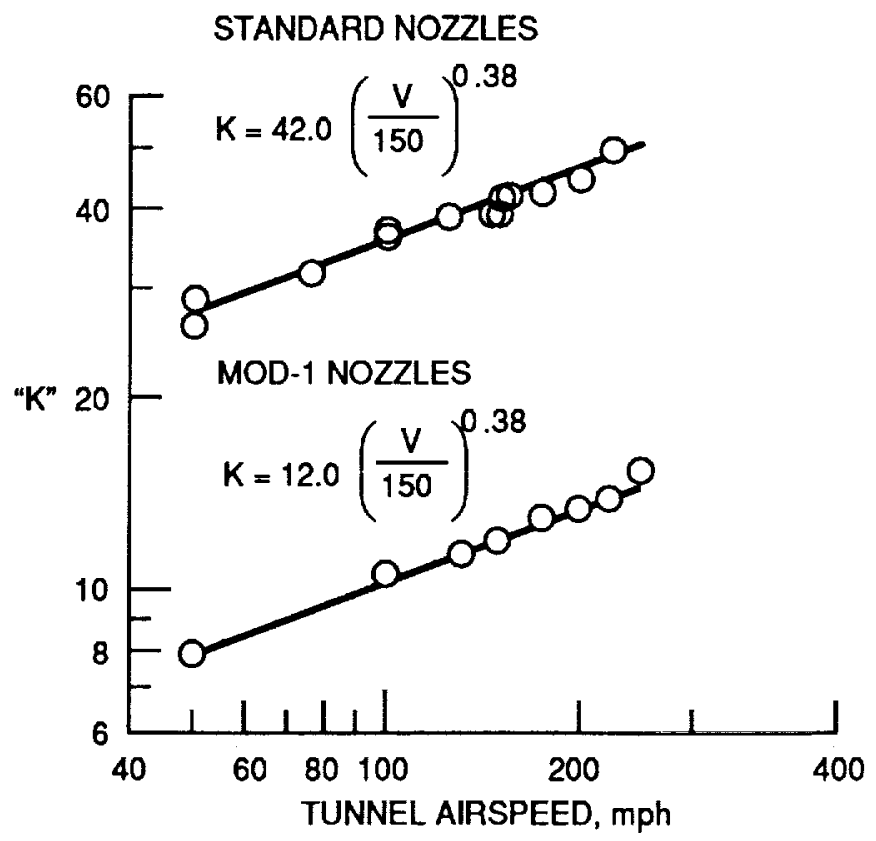

Figure 11. - Effect of tunnel airspeed on the liquid water content calibration constant "K". Air temperature $=0^{\circ} \mathrm{F}, \mathrm{MVD}=20$ microns. 


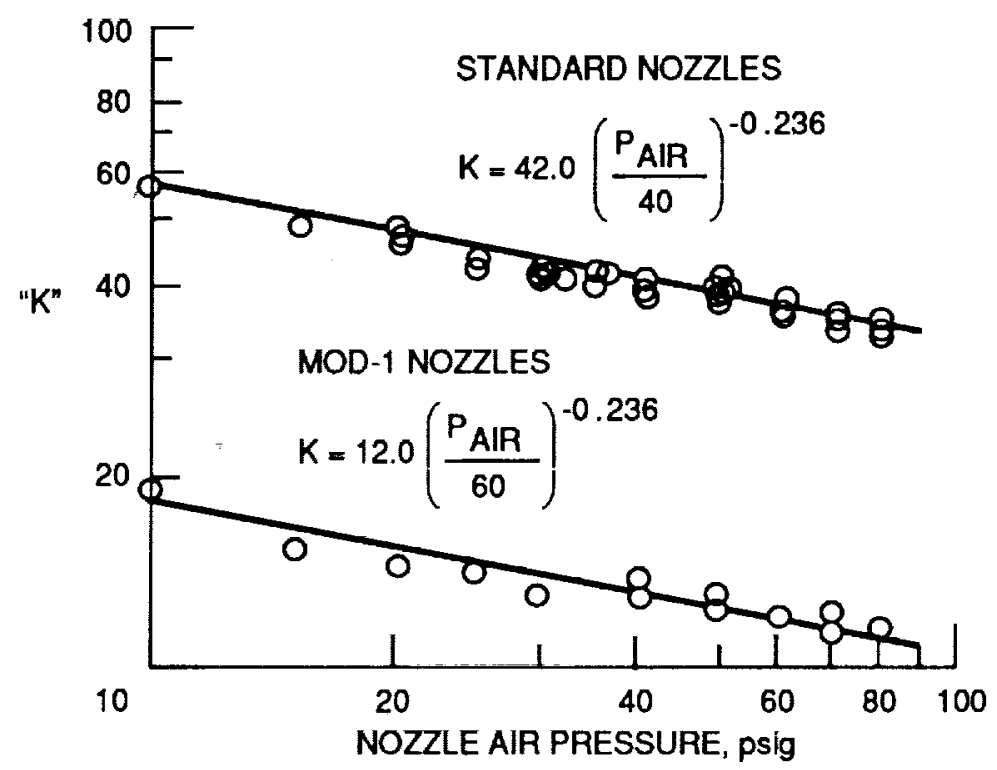

Figure 12. - Effect of nozzle air pressure on the liquid water content calibration constant " $\mathrm{K}$ ". Airspeed $=150 \mathrm{mph}$, MVD $=20$ microns.

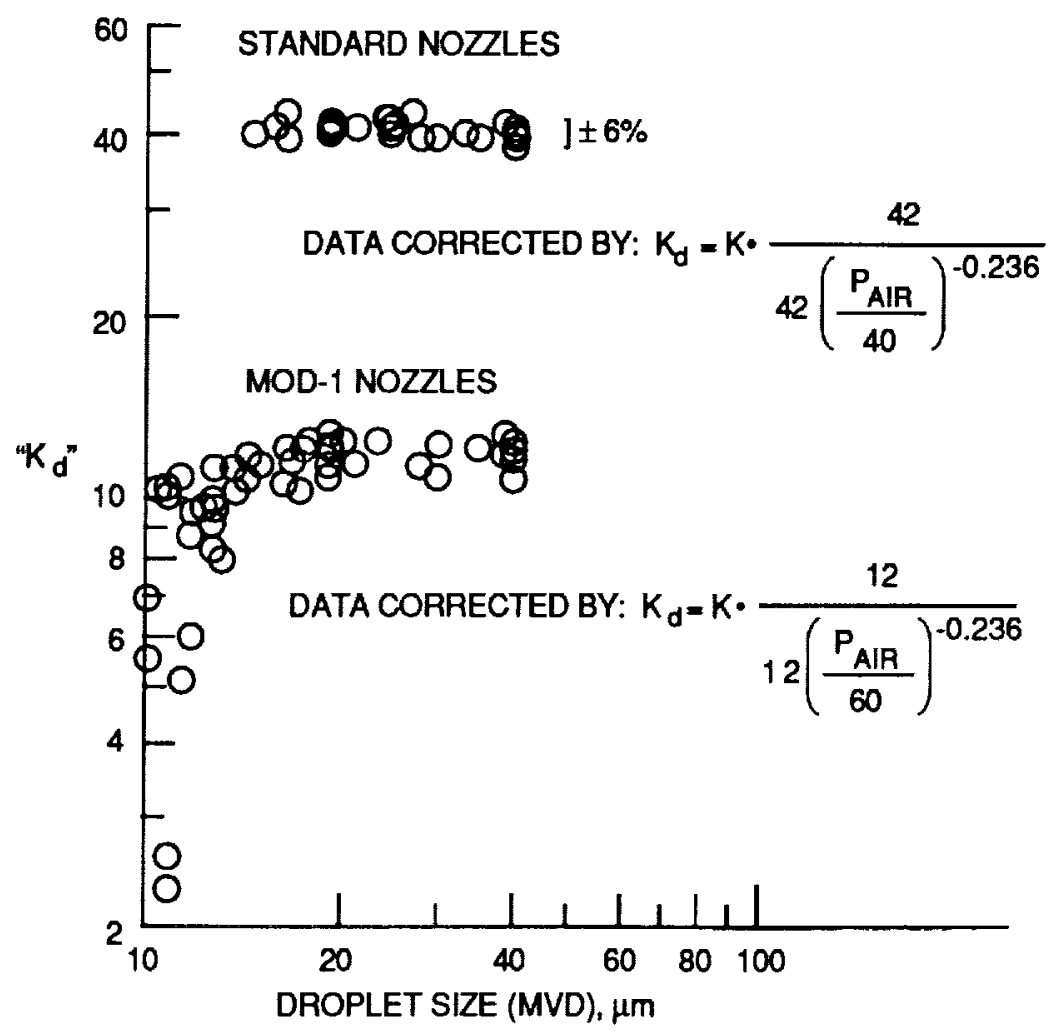

Figure 13. - Effect of droplet size on the liquid water content calibration constant " $K$ ". " $K_{d}$ " is the K corrected for changes in air pressure. Airspeed $=150 \mathrm{mph}$, air temperature $=0^{\circ} \mathrm{F}$. 


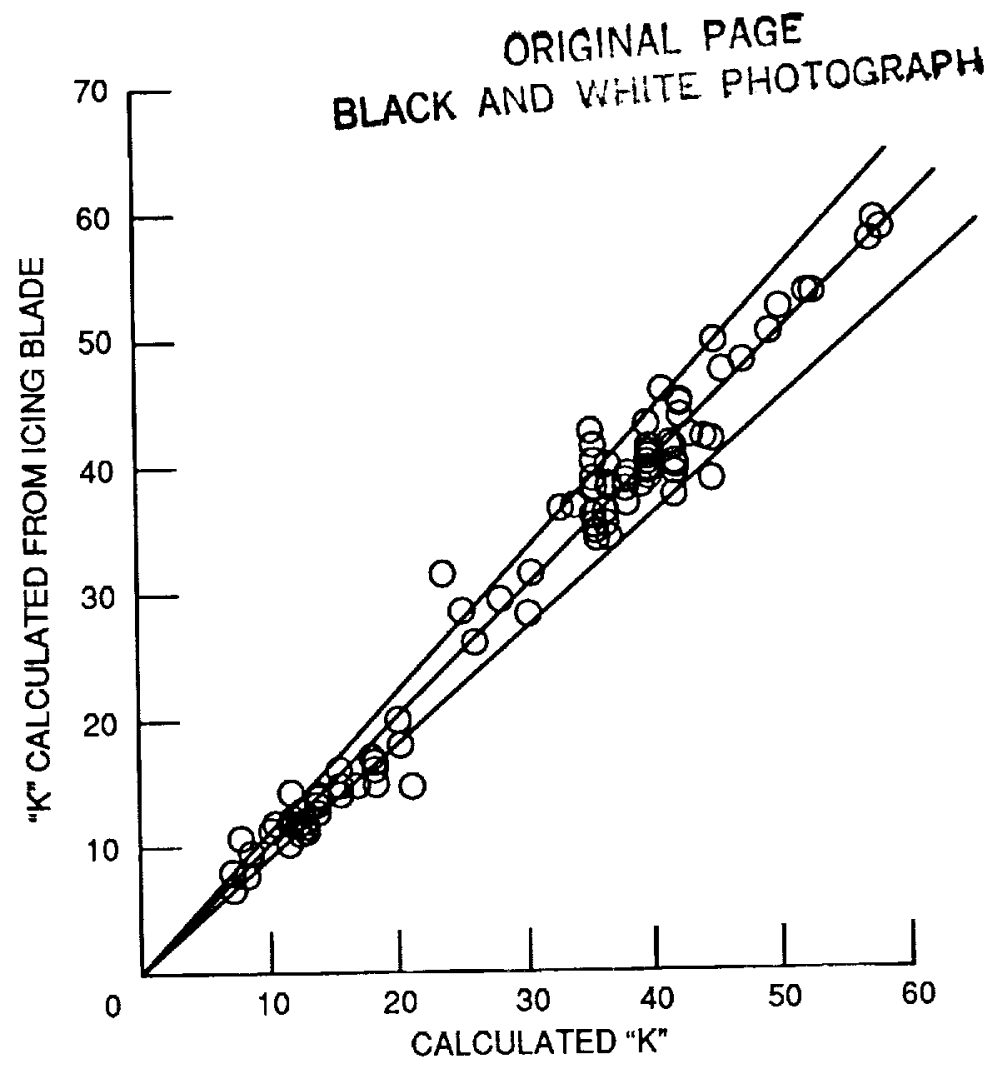

Figure 14. - Comparison of calculated and measured LWC calibration constant " $K$ ".

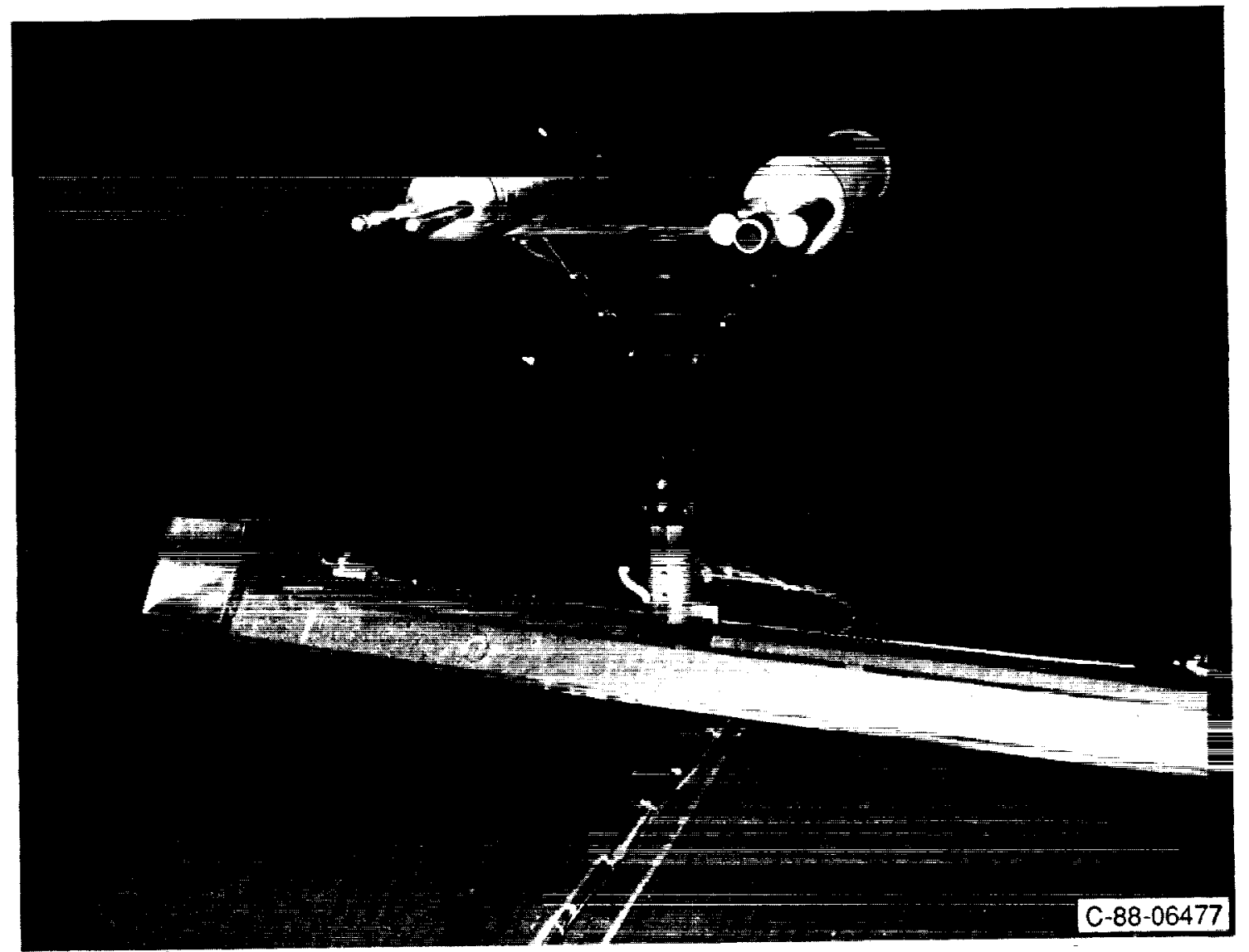

Figure 15. - Two droplet sizing instruments mounted on traversing mechanism. Optical Array Probe (left) and Forward Scattering Probe (right). 


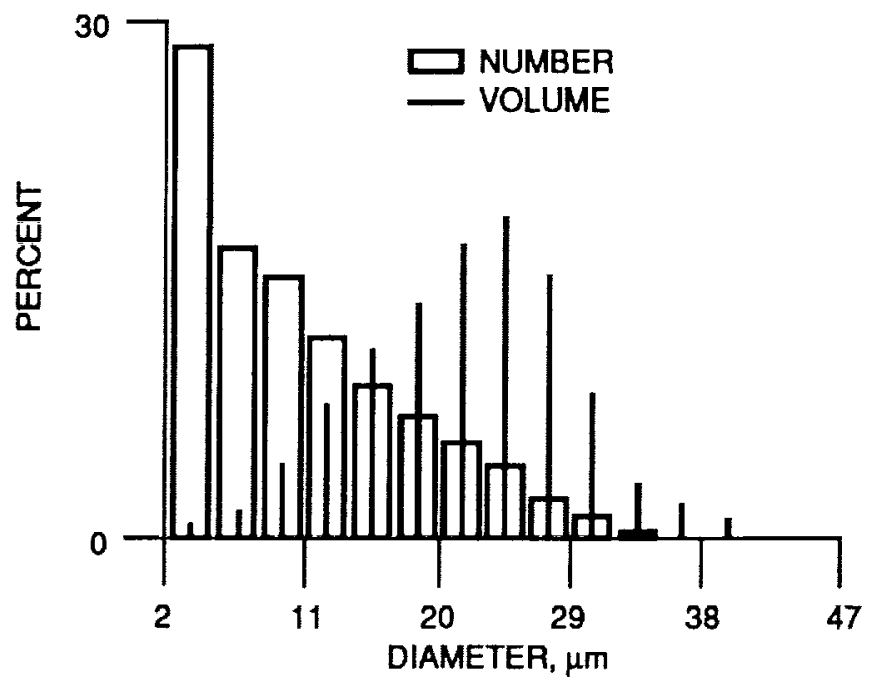

(a) FSSP.

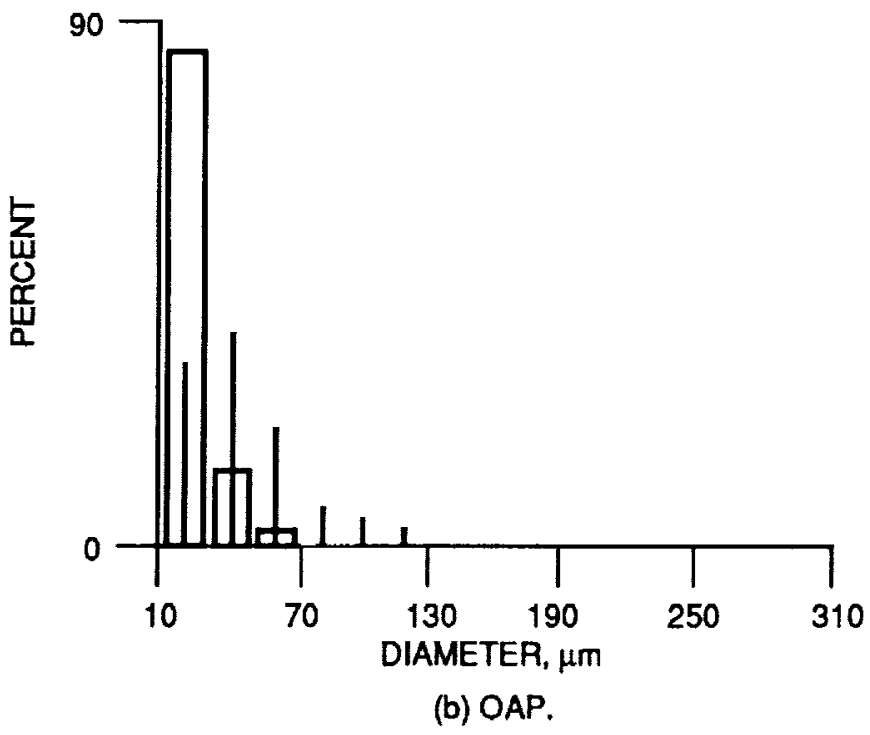

Figure 16. - Example of percent number and percent volume histograms from FSSP and OAP (MVD = 22.8 microns). 


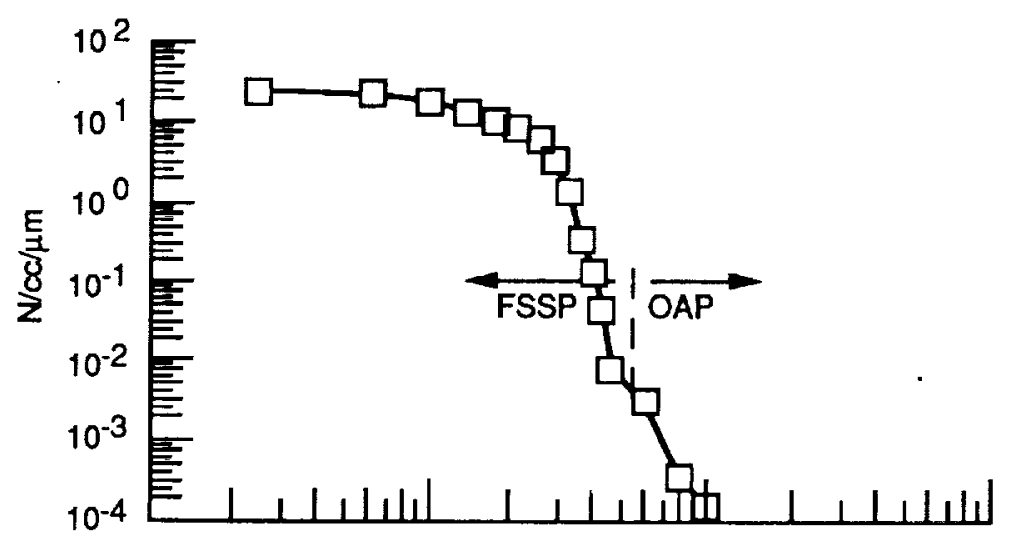

(a) Number distribution.

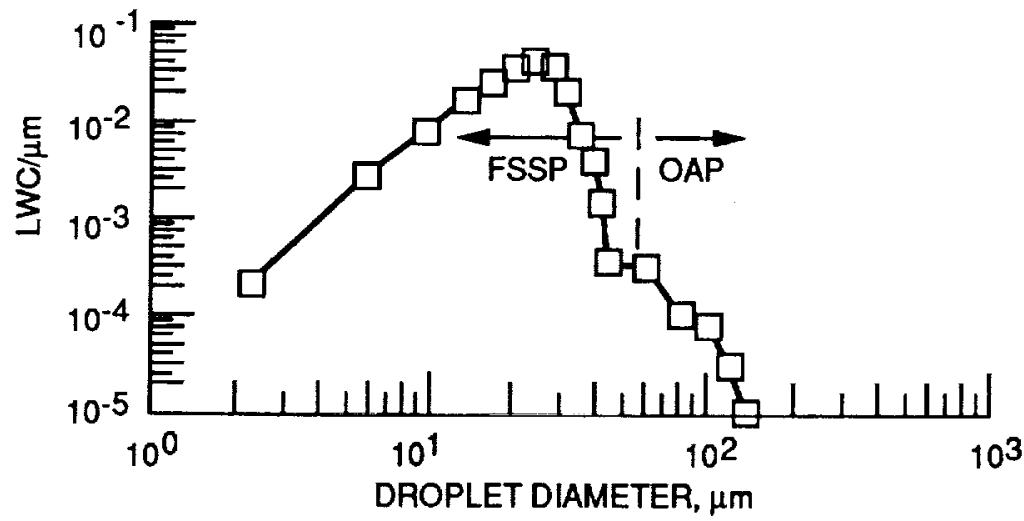

(b) LWC distribution.

Figure 17. - Number and LWC distribution from the FSSP/OAP. MVD $=22.8$ microns, airspeed $=150 \mathrm{mph}, \mathrm{P}_{\mathrm{AlR}}=60 \mathrm{psig}$, $\mathrm{dP}=40$ psid. 


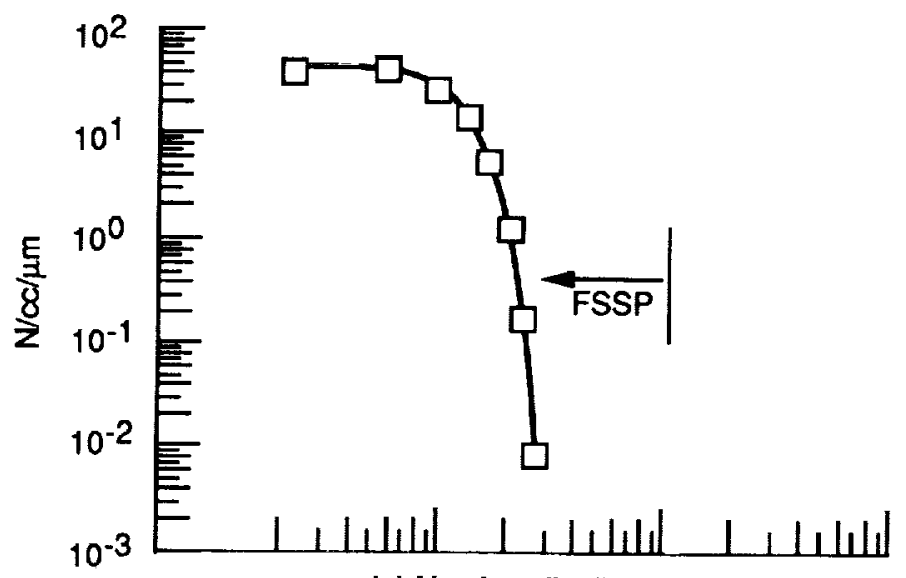

(a) Number distribution.

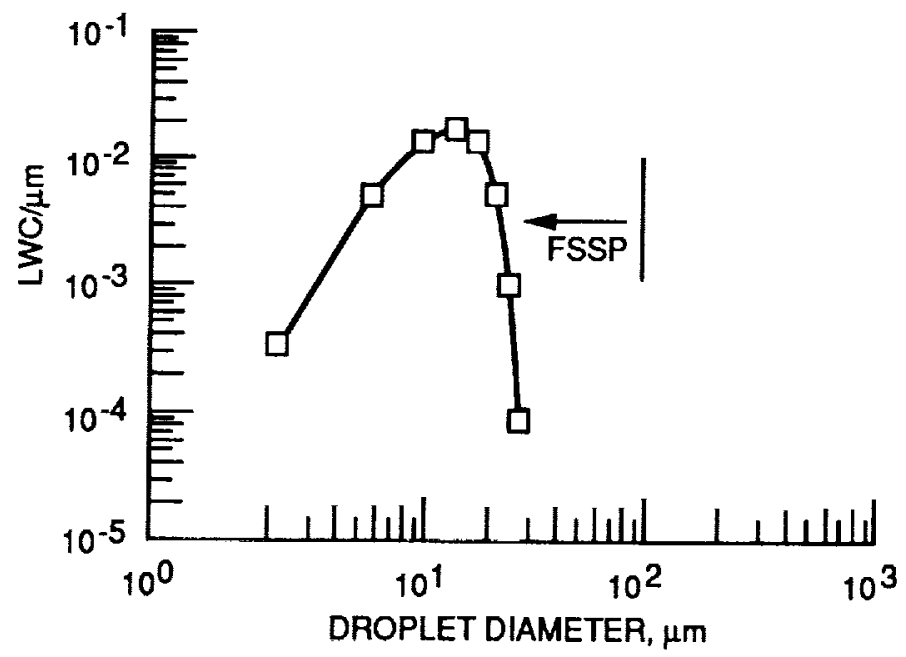

(b) LWC distribution.

Figure 18. - Number and LWC distribution from the FSSP/OAP. MVP $=13.0$ microns, airspeed $=$ $150 \mathrm{mph}, P_{\text {AIR }}=80$ psig, $d P=5$ psid. 


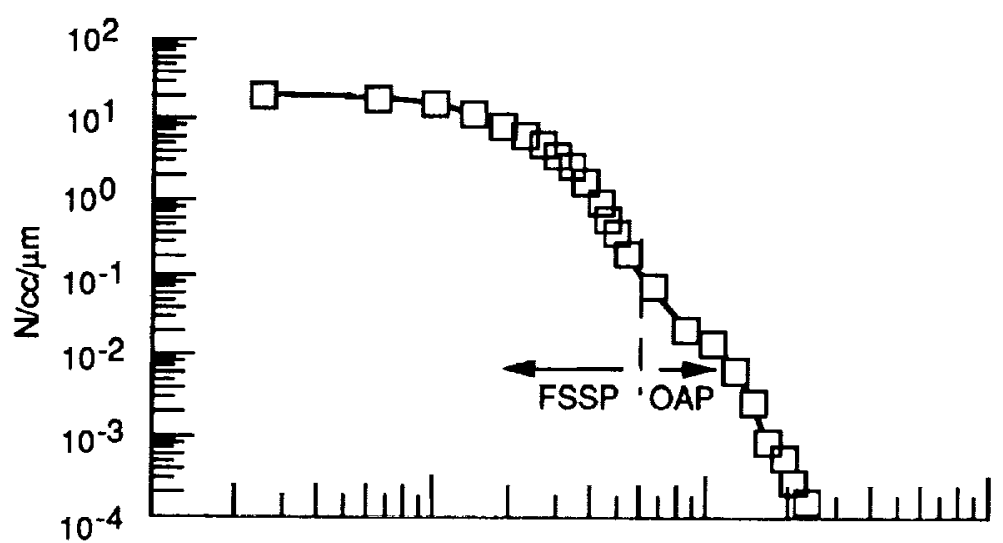

(a) Number distribution.

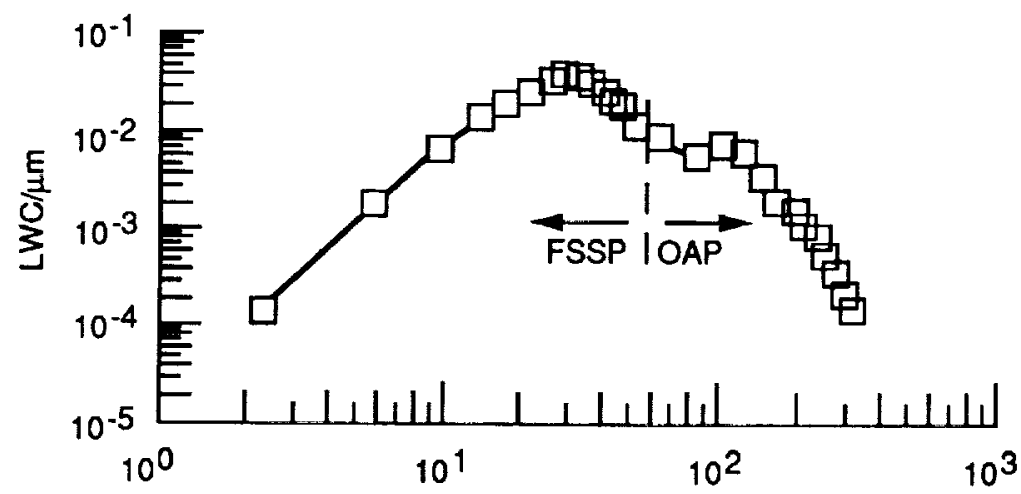

(a) Number distribution.

Figure 19. - Number and LWC distribution from the FSSP/OAP. $M V D=46.2$ microns, airspeed $=150 \mathrm{mph}, P_{A I R}=60 \mathrm{psig}$, $\mathrm{dP}=100$ psid. 


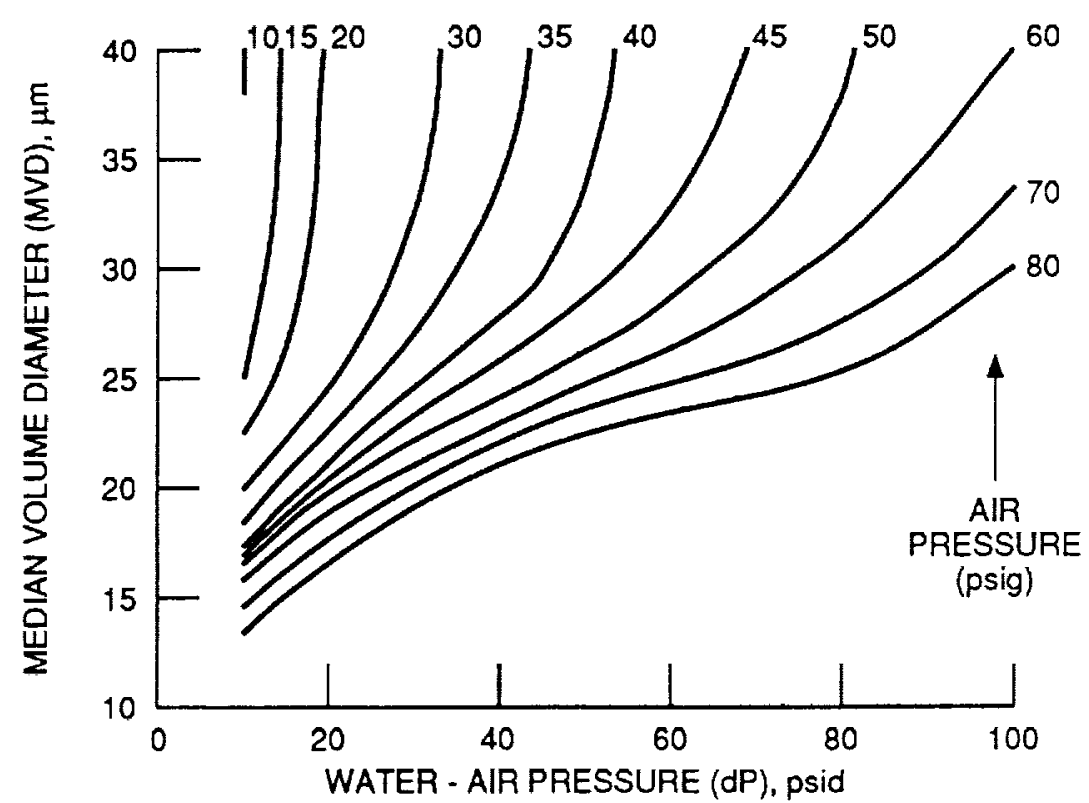

(a) Standard NASA nozzles.

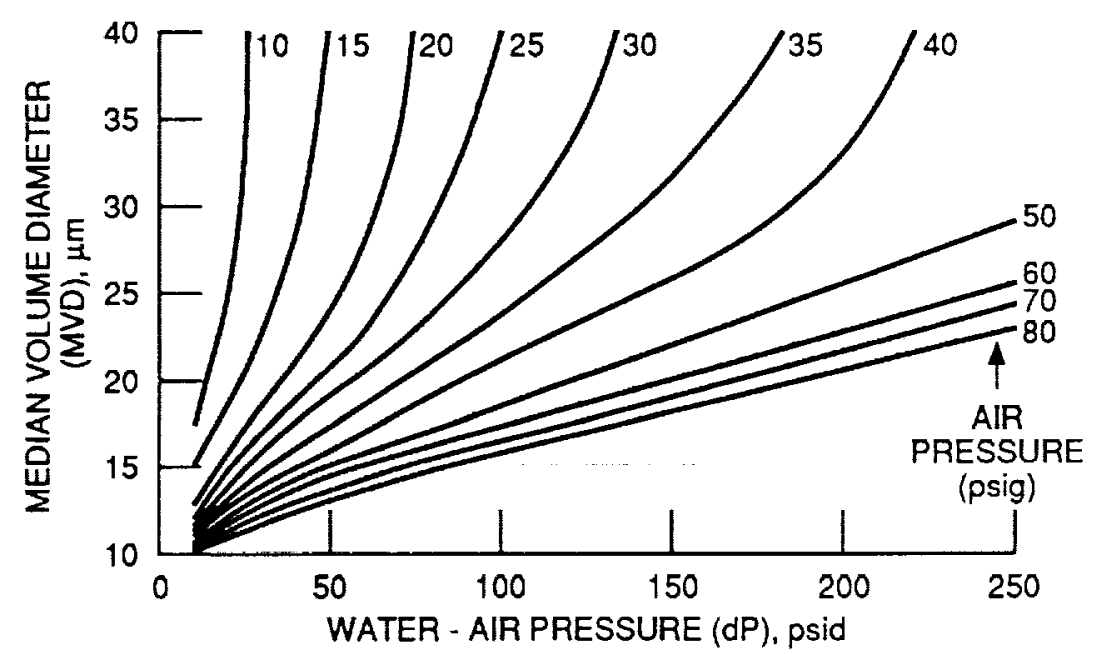

(b) MOD 1 nozzles.

Figure 20. - Droplet size calibration. 


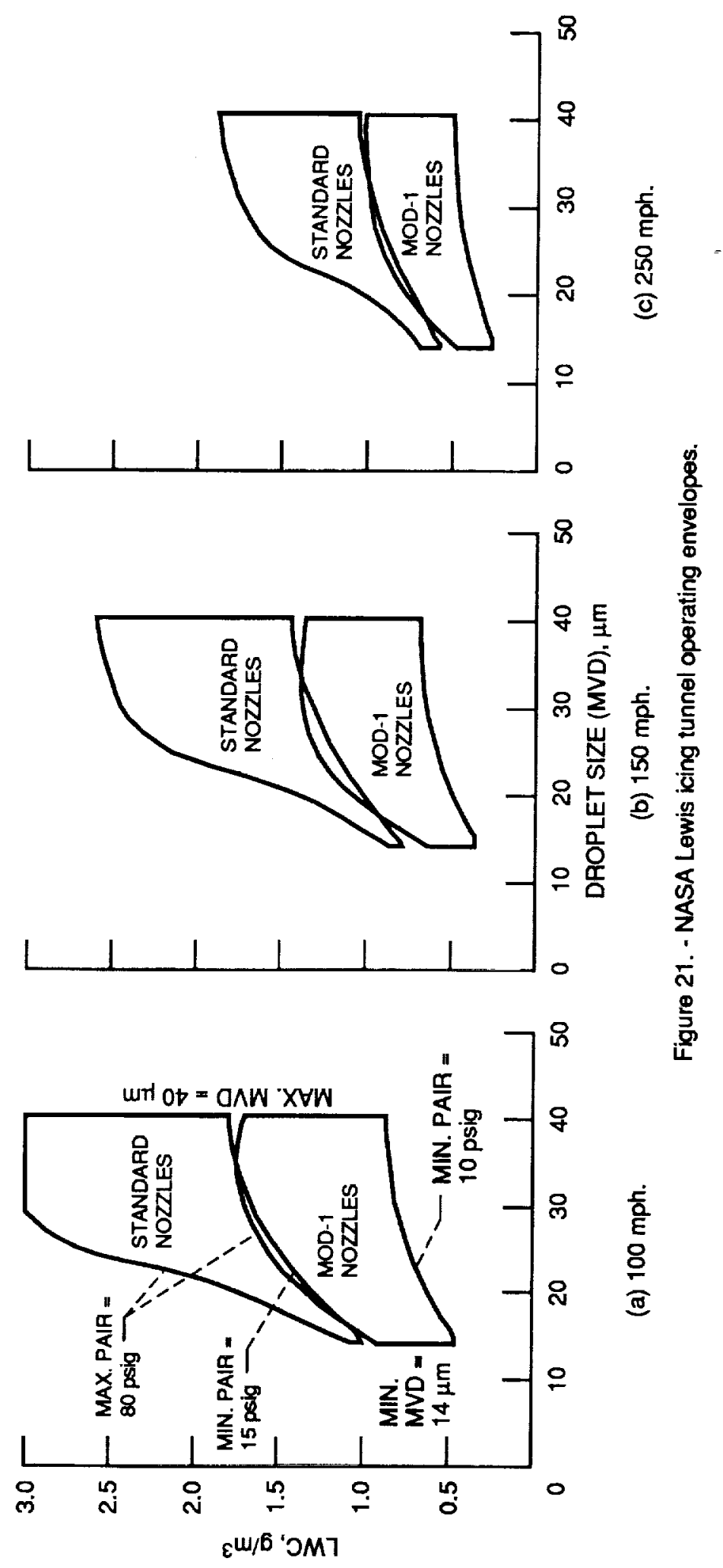




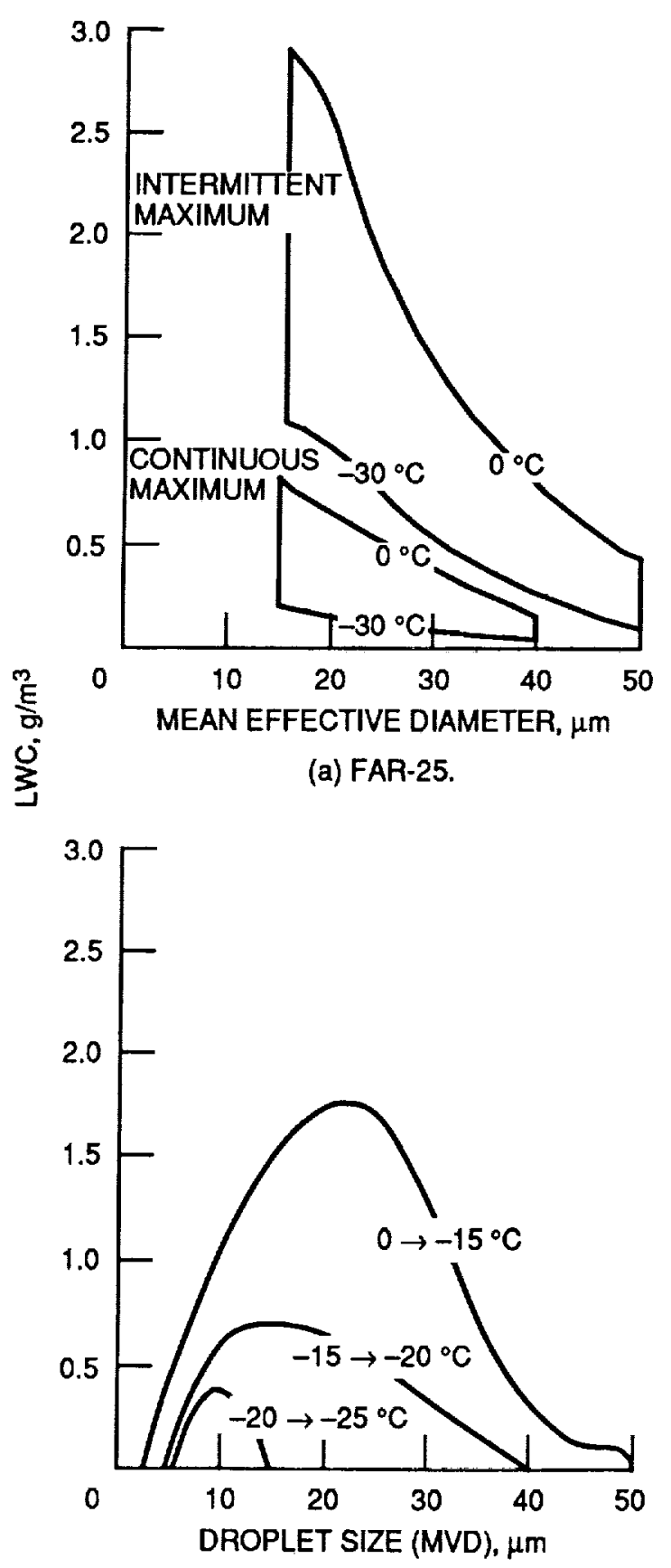

(b) FAR-29.

Figure 22. - FAA aircraft icing certification criteria.

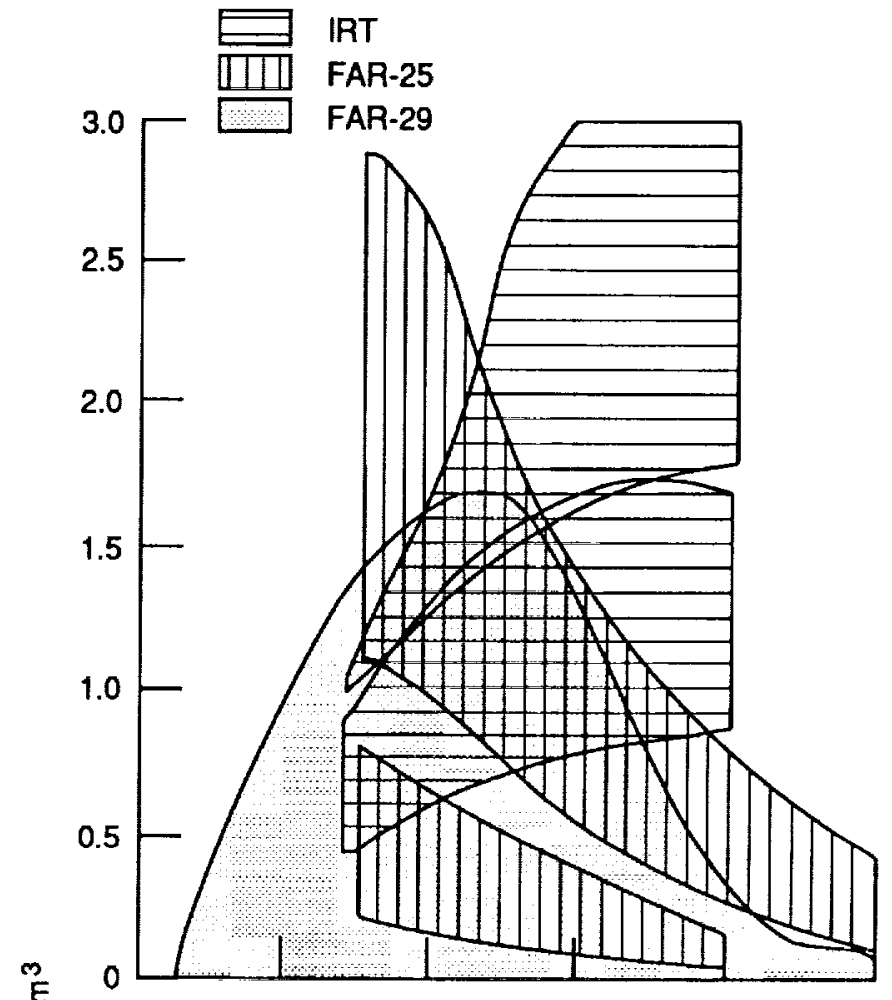

(a) $100 \mathrm{mph}$.

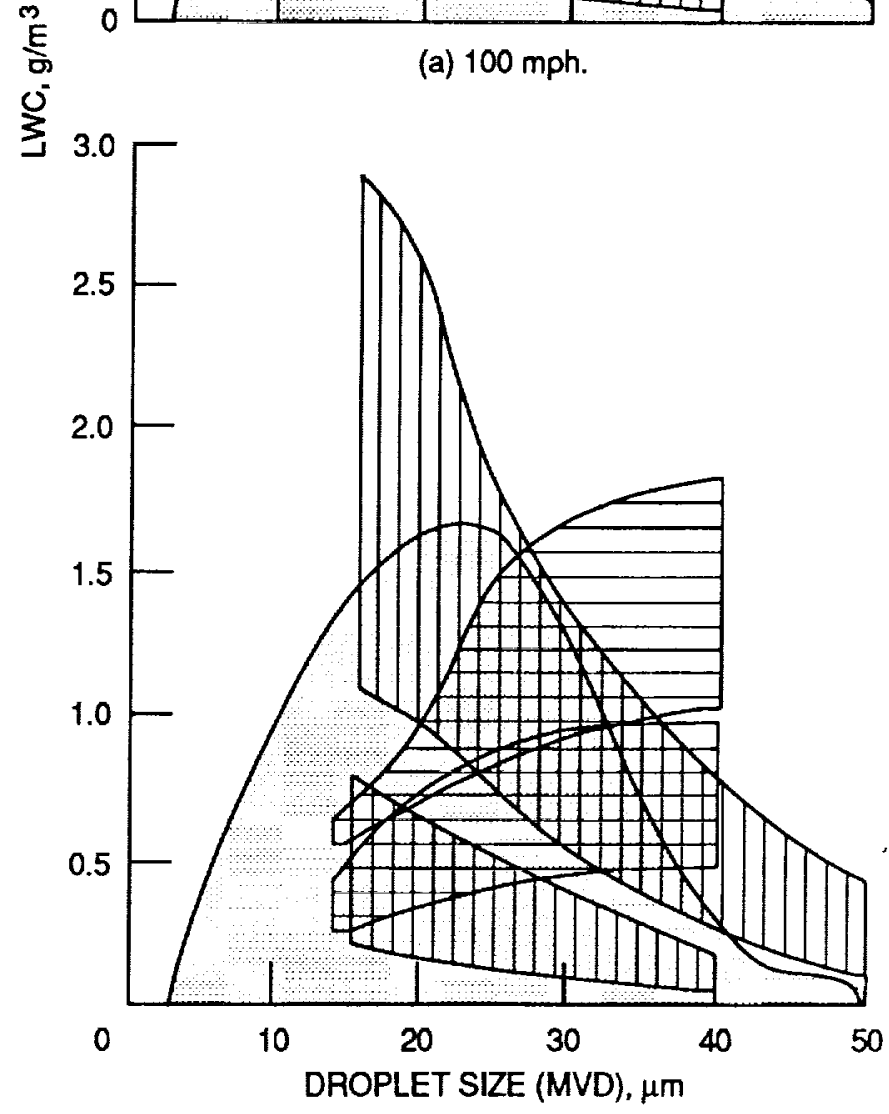

(b) $250 \mathrm{mph}$.

Figure 23. - Comparison of IRT operating envelope to FAA aircraft icing criteria. 


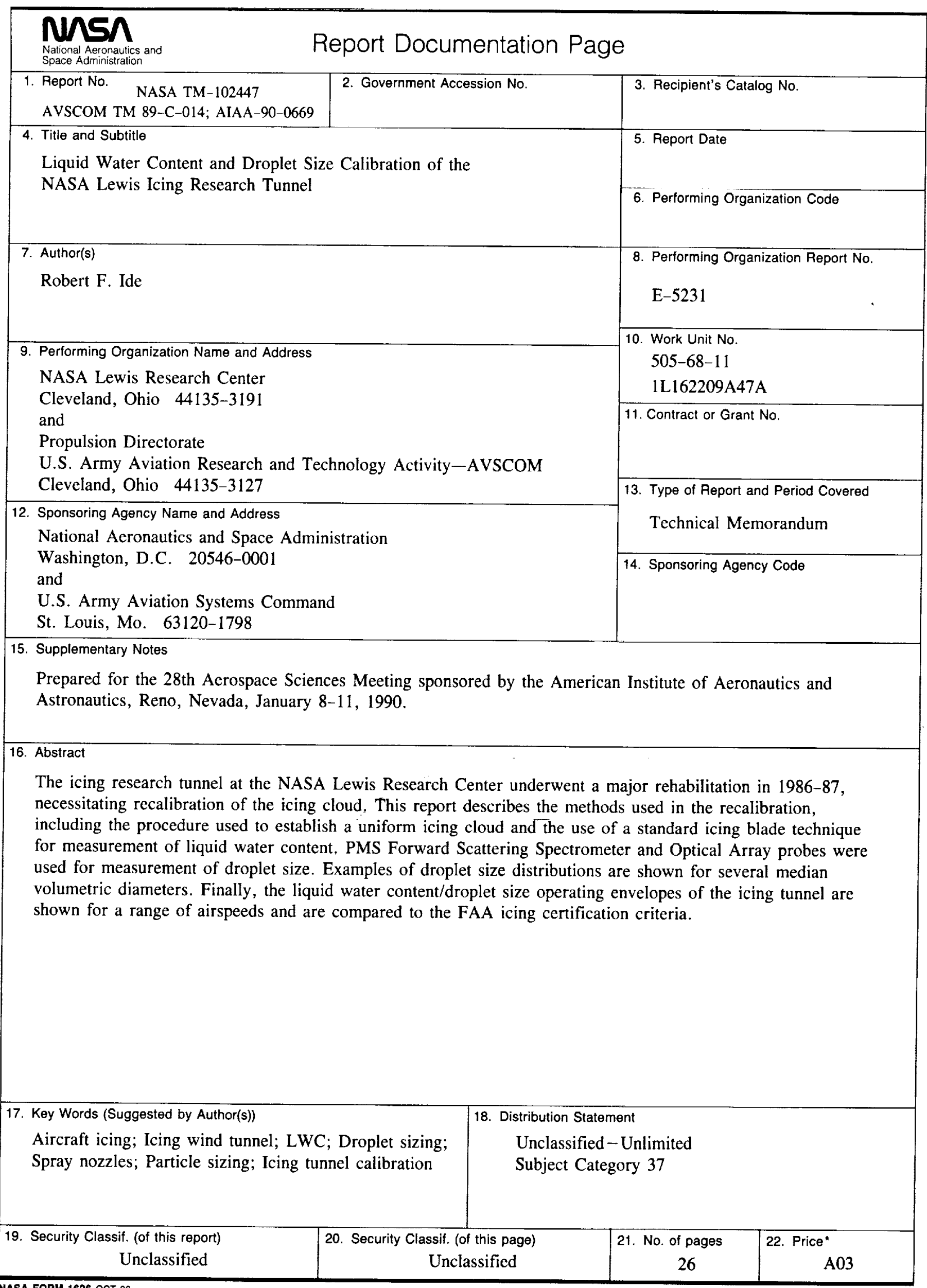

Performing Organization Name and Address

NASA Lewis Research Center

Cleveland, Ohio 44135-3191

Propulsion Directorate

U.S. Army Aviation Research and Technology Activity-AVSCOM

Cleveland, Ohio 44135-3127

National Acronautics and Space A

National Aeronautics and Space Administration

and

U.S. Army Aviation Systems Command

St. Louis, Mo. 63120-1798

Prepared for the 28th Aerospace Sciences Meeting sponsored by the American Institute of Aeronautics and Astronautics, Reno, Nevada, January 8-11, 1990.

\section{Abstract} including the procedure used to establish a uniform icing cloud and the use of a standard icing blade technique for measurement of liquid water content. PMS Forward Scattering Spectrometer and Optical Array probes were used for measurement of droplet size. Examples of droplet size distributions are shown for several median volumetric diameters. Finally, the liquid water content/droplet size operating envelopes of the icing tunnel are shown for a range of airspeeds and are compared to the FAA icing certification criteria.

Aircraft icing; Icing wind tunnel; LWC; Droplet sizing;

Spray nozzles; Particle sizing; Icing tunnel calibration
Unclassified - Unlimited

Subject Category 37 
